\title{
Comprehensive review of the detection methods for synthetic cannabinoids and cathinones
}

\author{
Akira Namera $\cdot$ Maho Kawamura $\cdot$ \\ Akihiro Nakamoto $\cdot$ Takeshi Saito $\cdot$ \\ Masataka Nagao
}

Received: 20 November 2014/ Accepted: 29 January 2015/Published online: 6 March 2015

(C) Japanese Association of Forensic Toxicology and Springer Japan 2015

\begin{abstract}
A number of $N$-alkyl indole or indazole-3-carbonyl analogs, with modified chemical structures, are distributed throughout the world as synthetic cannabinoids. Like synthetic cannabinoids, cathinone analogs are also abused and cause serious problems worldwide. Acute deaths caused by overdoses of these drugs have been reported. Various analytical methods that can cope with the rapid changes in chemical structures are required for routine analysis and screening of these drugs in seized and biological materials for forensic and clinical purposes. Although many chromatographic methods to analyze each drug have been published, there are only a few articles summarizing these analytical methods. This review presents the various colorimetric detections, immunochemical assays, gas chromatographic-mass spectrometric methods, and liquid chromatographic-mass spectrometric methods proposed for the analysis of synthetic cannabinoids and cathinones.
\end{abstract}

Keywords Synthetic cannabinoids - Cannabimimetics . Cathinones · GC-MS-MS · LC-MS-MS · Analytical methods

A. Namera $(\bowtie) \cdot$ M. Nagao

Department of Forensic Medicine, Institute of Biomedical and Health Sciences, Hiroshima University, 1-2-3 Kasumi, Minamiku, Hiroshima 734-8553, Japan

e-mail: namera@hiroshima-u.ac.jp

M. Kawamura · A. Nakamoto

Forensic Science Laboratory, Hiroshima Prefectural Police

Headquarters, Hiroshima, Japan

T. Saito

Department of Emergency and Critical Care Medicine, Tokai University School of Medicine, Isehara, Japan

\section{Abbreviations}

A-796260

A-834735

AB-001

AB-005

AB-CHMINACA

AB-FUBINACA

AB-PINACA

ADB-FUBINACA

ADBICA

ADB-PINACA

AM-1220
[1-[2-(4-Morpholinyl)ethyl]-1Hindol-3-yl] $(2,2,3,3-$

tetramethylcyclopropyl)methanone

[1-[(Tetrahydro-2H-pyran-4-

yl)methyl]-1 $H$-indol-3-yl](2,2,3,3-

tetramethylcyclopropyl)-

methanone

Adamantan-1-yl(1-pentyl-1H-indol3-yl)methanone

[1-[(1-Methyl-2-piperidinyl)methyl]$1 H$-indol-3-yl](2,2,3,3-

tetramethylcyclopropyl)methanone

$N$-[(1S)-1-(Aminocarbonyl)-

2-methylpropyl]-1-

(cyclohexylmethyl)-1H-indazole-3-

carboxamide

$N$-(1-Amino-3-methyl-1-oxobutan-2-

yl)-1-(4-fluorobenzyl)- $1 H$-indazole-

3-carboxamide

$\mathrm{N}$-(1-Amino-3-methyl-1-oxobutan-2-

yl)-1-pentyl- $1 H$-indazole-3-

carboxamide

$N$-(1-Amino-3,3-dimethyl-1-

oxobutan-2-yl)-1-(4-fluorobenzyl)-

$1 H$-indazole-3-carboxamide

$N$-(1-Amino-3,3-dimethyl-1-

oxobutan-2-yl)-1-pentyl- $1 H$-indole-

3-carboxamine

$N$-(1-Amino-3,3-dimethyl-1-

oxobutan-2-yl)-1-pentyl- $1 H$ -

indazole-3-carboxamide

[1-[(1-Methylpiperidin-2-yl)methyl]-

$1 H$-indol-3-yl]-(naphthalen-1-

yl)methanone 
AM-1248

AM-1241

AM-2201

AM-2233

AM-679

AM-694

AMB

APICA

APINACA

Cathinone

CI

EI

ELISA

ESI

FDU-PB-22

5F-PB-22

FUB-PB-22

GC

GC-MS

GC-MS-MS

HU-210

JWH-015

JWH-018

JWH-019

JWH-030

JWH-073
Adamantan-1-yl[1-[(1-methyl-2piperidinyl)methyl]-1 $H$-indol-3yl]methanone

(2-Iodo-5-nitrophenyl)-[1-(1methylpiperidin-2-ylmethyl)-1Hindol-3-yl]methanone

[1-(5-Fluoropentyl)- $1 H$-indol-3-yl]1-naphthalenylmethanone

(2-Iodophenyl)[1-[(1-methyl-2piperidinyl)methyl]- $1 H$-indol-3-yl]methanone

(2-Iodophenyl)(1-pentyl-1H-indol-3yl)methanone

1-[(5-Fluoropentyl)-1H-indol-3-yl](2-iodophenyl)methanone

Methyl (1-pentyl-1H-indazole-3carbonyl)-L-valinate

$\mathrm{N}$-(1-Adamantyl)-1-pentyl-1Hindole-3-carboxamide

$\mathrm{N}$-(1-Adamantyl)-1-pentyl-1Hindazole-3-carboxamide

2-Amino-1-phenylpropan-1-one

Chemical ionization

Electron ionization

Enzyme-linked immunosorbent assay

Electrospray ionization

Naphthalen-1-yl 1-(4-fluorobenzyl)-

$1 H$-indole-3-carboxylate

1-(5-Fluoropentyl)-8-quinolinyl ester-1H-indole-3-carboxylic acid

Quinolin-8-yl-1-(4-fluorobenzyl)-1 $H$ indole-3-carboxylate

Gas chromatography

Gas chromatography-mass

spectrometry

Gas chromatography-tandem mass

spectrometry

3-(1,1'-Dimethylheptyl)-

$6 a R, 7,10,10 a R$-tetrahydro-1-

hydroxy-6,6-dimethyl-6H-

dibenzo[ $b, d]$ pyran-9-methanol

1-Naphthalenyl(2-methyl-1-propyl-

$1 H$-indol-3-yl)methanone

1-Naphthalenyl(1-pentyl-1 $H$-indol-3-

yl)methanone

1-Naphthalenyl(1-hexyl-1H-indol-3-

yl)methanone

1-Naphthalenyl(1-pentyl-1H-pyrrol-

3-yl)methanone

1-Naphthalenyl(1-butyl-1H-indol-3yl)methanone
JWH-200

JWH-203

JWH-250

JWH-251

JWH-307

LC

LC-MS

LC-MS-MS

LLE

LOD

LOQ

MAM-2201

MDPBP

MDPPP

MDPV

MN-18

MOPPP

NM-2201

NMR

NNEI

MPBP

MPHP

MPPP

MRM

MS

MS-MS

NPB-22

$\alpha$-PBP

$\alpha$-PHP

PP

$\alpha$-PPP

PTFE
1-Naphthalenyl[1-[2-(4-

morpholinyl)ethyl]-1 $H$-indol-3-

yl]methanone

2-(2-Chlorophenyl)-1-(1-pentyl-1Hindol-3-yl)ethanone

2-(2-Methoxyphenyl)-1-(1-pentyl-

$1 H$-indol-3-yl)ethanone

2-(2-Methylphenyl)-1-(1-pentyl-1 $H$ -

indol-3-yl)ethanone

[5-(2-Fluorophenyl)-1-pentyl-1H-

pyrrol-3-yl](naphthalene-1-

yl)methanone

Liquid chromatography

Liquid chromatography-mass

spectrometry

Liquid chromatography-tandem mass

spectrometry

Liquid-liquid extraction

Limit of detection

Limit of quantification

[1-(5-Fluoropentyl)-1 $H$-indol-3-

yl](4-methyl-1-

naphthalenyl)methanone

$3^{\prime}, 4^{\prime}$-Methylenedioxy- $\alpha$ -

pyrrolidinobutiophenone

$3^{\prime}, 4^{\prime}$-Methylenedioxy- $\alpha$ -

pyrrolidinopropiophenone

3,4-Methylenedioxypyrovalerone

$\mathrm{N}$-1-Naphthalenyl-1-pentyl- $1 \mathrm{H}$ -

indazole-3-carboxamide

4'-Methoxy- $\alpha$ -

pyrrolidinopropiophenone

Naphthalen-1-yl 1-(5-fluoropentyl)-

$1 \mathrm{H}$-indole-3-carboxylate

Nuclear magnetic resonance

$\mathrm{N}$-1-Naphthalenyl-1-pentyl-1 $\mathrm{H}$ -

indole-3-carboxamide

4'-Methyl- $\alpha$-pyrrolidinobutiophenone

$4^{\prime}$-Methyl- $\alpha$ -

pyrrolidinohexanophenone

4'-Methyl- $\alpha$ -

pyrrolidinopropiophenone

Multiple reaction monitoring

Mass spectrometry

Tandem mass spectrometry

8-Quinolinyl 1-pentyl-1 $H$-indazole-

3-carboxylate

$\alpha$-Pyrrolidinobutiophenone

$\alpha$-Pyrrolidinohexanophenone

Protein precipitation

$\alpha$-Pyrrolidinopropiophenone

Polytetrafluoroethylene 


\begin{tabular}{|c|c|}
\hline PV8 & $\begin{array}{l}\text { 1-Phenyl-2-(pyrrolidin-1-yl)heptan- } \\
\text { 1-one }\end{array}$ \\
\hline PV9 & $\begin{array}{l}\text { 1-Phenyl-2-(pyrrolidin-1-yl)octan-1- } \\
\text { one }\end{array}$ \\
\hline$\alpha-P V P$ & $\begin{array}{l}\text { 1-Phenyl-2-(pyrrolidin-1-yl)pentan- } \\
\text { 1-one, } \alpha \text {-pyrrolidinovalerophenone }\end{array}$ \\
\hline PX1 & $\begin{array}{l}(S)-N \text {-(1-Amino-1-oxo-3- } \\
\text { phenylpropan-2-yl)-1-(5- } \\
\text { fluoropentyl)- } 1 H \text {-indole-3- } \\
\text { carboxamide }\end{array}$ \\
\hline QUPIC & $\begin{array}{l}\text { Quinolin-8-yl 1-pentyl-1H-indole-3- } \\
\text { carboxylate }\end{array}$ \\
\hline QUCHIC & $\begin{array}{l}\text { Quinolin-8-yl 1-(cyclohexylmethyl)- } \\
1 H \text {-indole-3-carboxylate }\end{array}$ \\
\hline RCS-4 & $\begin{array}{l}\text { (4-Methoxyphenyl)(1-pentyl-1H- } \\
\text { indol-3-yl)methanone }\end{array}$ \\
\hline SDB-005 & $\begin{array}{l}\text { Naphthalen-1-yl 1-pentyl-1H- } \\
\text { indazole-3-carboxylate }\end{array}$ \\
\hline SIM & Selected ion monitoring \\
\hline SPE & Solid-phase extraction \\
\hline SPME & Solid-phase microextraction \\
\hline SRM & Selected reaction monitoring \\
\hline THJ-018 & $\begin{array}{l}\text { 1-Naphthalenyl(1-pentyl-1H-indazol- } \\
\text { 3-yl)methanone }\end{array}$ \\
\hline THJ-2201 & $\begin{array}{l}\text { [1-(5-Fluoropentyl)-1H-indazol-3- } \\
\text { yl](naphthalen-1-yl)methanone }\end{array}$ \\
\hline TLC & Thin-layer chromatography \\
\hline TOFMS & Time-of-flight mass spectrometry \\
\hline UV & Ultraviolet \\
\hline UR-144 & $\begin{array}{l}\text { (1-Pentyl- } 1 H \text {-indol-3-yl)(2,2,3,3- } \\
\text { tetramethylcyclopropyl)methanone }\end{array}$ \\
\hline XLR-11 & $\begin{array}{l}\text { [1-(5-Fluoropentyl)-1H-indol-3- } \\
\text { yl](2,2,3,3- } \\
\text { tetramethylcyclopropyl)methanone }\end{array}$ \\
\hline
\end{tabular}

XLR-12 (2,2,3,3-Tetramethylcyclopropyl)[1(4,4,4-trifluorobutyl)-1 $\mathrm{H}$-indol-3yl]methanone

\section{Introduction}

Currently, many illegal drugs are abused worldwide, with serious social problems arising as a consequence. Although various stimulants and narcotics have been in use to date, new drugs targeting cannabinoid receptors have been abused since their existence in herbal mixtures was disclosed in 2008 [1]. HU-210, a synthetic classical cannabinoid, and cyclohexylphenols were commonly used as recreational drugs, but mainstream use has since changed to $\mathrm{N}$-alkyl indole-3-carbonyl derivatives, such as drugs of the JWH and AM series (Fig. 1), because their activities are stronger than those of the conventional cannabinoids. These compounds are called cannabimimetics or synthetic cannabinoids and can be purchased as "spice" or "K2" in the drug market or via the Internet. Cathinones, also known as "bath salts" or "plant food," are psychoactive drugs and are also abused as recreational drugs. The parent compound, cathinone, is a well-known stimulant, and can be isolated from the khat plant or produced by synthetic means. Cathinone analogs with high selectivity and strong activity for serotonin receptors and monoamine transporters have been distributed in the drug market (Fig. 2). The prevalence of cannabinoid and cathinone abuse in many countries has been reviewed elsewhere [2-7].

Although the same substances are distributed throughout the world, the times at which they are abused tend to vary depending on whether the substances are controlled by local laws. As shown in the reviews [2-7], new analogs appear in the drug market just after the preceding drug comes under regulation. Although many such substances are controlled in countries throughout the world, the regulations are usually limited by the structures of the drugs. Therefore, when the structure of a side chain or substitution is slightly different from that of the regulated drug, the analog is regarded as being beyond the scope of the regulation. These emerging drugs always show psychoactive actions because their chemical structures are similar to those of the drugs being controlled. However, the detailed pharmacological activities of these analogs are not known, which makes access easy and use of these drugs very dangerous to human health.

Although many researchers have focused on the development of detection methods, only a few analytical reviews that summarize the systematic identification and quantification techniques for these drugs have appeared [8-10]. In this review, we summarize the various techniques for the detection of synthetic cannabinoids and cathinones that have been published up to 2014, including colorimetric, immunochemical, and chromatographic methods.

\section{Synthetic cannabinoids}

\section{Colorimetric detection}

The Duquenois-Levine color test, which is used to identify classical cannabinoids such as $\Delta^{9}$-tetrahydrocannabinol, is negative for the synthetic cannabimimetics. The van Urk color test, which is used to identify indole-containing drugs of abuse, is also negative for these compounds. The use of 2,4-dinitrophenylhydrazine, which reacts with a keto moiety, is capable of reacting with synthetic cannabimimetics, such as the naphthoylindole, phenylacetylindole, benzoylindole, and cyclopropylindole classes, either in powder form or adsorbed onto plant material, and a positive test solution turns from yellow to orange. Although the LOD concentration was not detailed in the article, the solution 
Indole 3-carbonyl derivatives<smiles>[R]C(=O)c1c([R])n([R])c2ccccc12</smiles>

\begin{tabular}{llll}
\hline & $\mathbf{R}_{\mathbf{1}}$ & $\mathbf{R}_{\mathbf{2}}$ & $\mathbf{R}_{\mathbf{3}}$ \\
\hline JWH-015 & $n$-Propyl & Methyl & 1-Naphthyl \\
JWH-018 & $n$-Pentyl & $\mathrm{H}$ & 1-Naphthyl \\
AM-1220 & (1-Methyl-2-piperidinyl)methyl & $\mathrm{H}$ & 1-Naphthyl \\
JWH-200 & 2-(4-Morpholinyl)ethyl & $\mathrm{H}$ & 1-Naphthyl \\
JWH-203 & $n$-Pentyl & $\mathrm{H}$ & 2-Chloro-benzyl \\
JWH-250 & $n$-Pentyl & $\mathrm{H}$ & 2-Methoxy-benzyl \\
JWH-251 & $n$-Pentyl & $\mathrm{H}$ & 2-Methoxy-benzyl \\
RCS-4 & $n$-Pentyl & $\mathrm{H}$ & 4-Methoxy-phenyl \\
AB-001 & $n$-Pentyl & $\mathrm{H}$ & Adamantyl \\
AM-1248 & $($ 1-Methyl-2-piperidinyl)methyl & $\mathrm{H}$ & Adamantyl \\
AM-679 & $n$-Pentyl & $\mathrm{H}$ & 2-Iodo-phenyl \\
AM-694 & 5-Fluoro- $n$-pentyl & $\mathrm{H}$ & 2-Iodo-phenyl \\
AM-2233 & $($ 1-Methyl-2-piperidinyl)methyl & $\mathrm{H}$ & 2-Iodo-phenyl \\
AM-1241 & (1-Methyl-2-piperidinyl)methyl & $\mathrm{H}$ & 2-Iodo-5-nitro-phenyl \\
- a & 5-Fluoro- $n$-pentyl & $\mathrm{H}$ & 3-Pyridinoyl \\
\hline
\end{tabular}<smiles>CCn1cc(C(=O)C2C(C)(C)C2(C)C)c2ccccc21</smiles>

\begin{tabular}{ll}
\hline & $\mathbf{R}_{\mathbf{1}}$ \\
\hline UR-144 & $n$-Pentyl \\
XLR-11 & 5-Fluoro- $n$-pentyl \\
XLR-12 & 4,4,4-Trifluoro-butyl \\
AB-005 & (1-Methyl-2-piperidinyl)methyl \\
A-834735 & (Tetrahydro-2H-pyran-4-yl)methyl \\
A-796260 & 2-(4-Morpholinyl)ethyl \\
\hline
\end{tabular}

a No abbreviated name available

Pyrrole 3-carbonyl derivatives

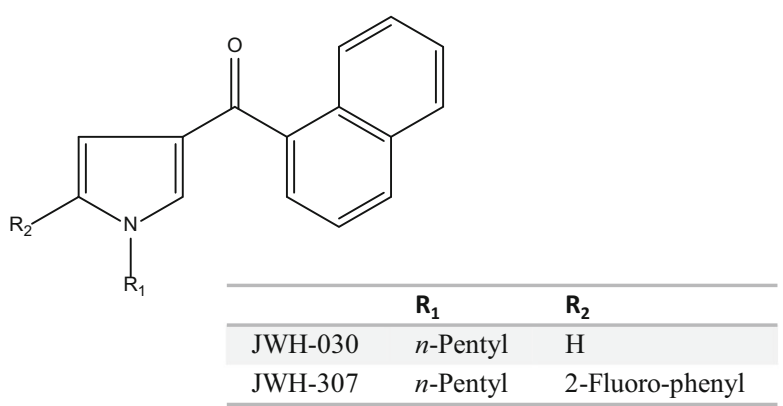

Indazole 3-carbonyl derivative<smiles>[R]C(=O)c1nn([R1])c2ccccc12</smiles>

Fig. 1 Structures of synthetic cannabinoids

tested contained at least $10 \mathrm{mg}$ of cannabimimetic powder suspended in methanol $(1 \mathrm{ml})$ [11]. The Marquis reagent, which reacts with all nitrogen-containing drugs, is positive for cyclohexylphenols and the JWH series. Although Dragendorff reagent is also positive for the JWH series, its LOD concentration is higher than that of Marquis reagent. Fast blue $\mathrm{BB}$ reacts with cyclohexylphenols, and the LOD concentration is not lower than that of Marquis reagent [12]. Iodoplatinate is also used as a detection reagent after TLC [13]. Although it is possible to detect synthetic cannabinoids with each reagent in these screening tests, it is difficult to detect small amounts or mixtures of synthetic cannabinoids.
Immunochemical detection

ELISAs developed in-house could be calibrated at $5 \mathrm{ng} / \mathrm{ml}$ with the 5-OH and 4-OH metabolites of JWH-018 and JWH-250, respectively, and evaluated for the detection of synthetic cannabinoids in urine [14]. Recently, some commercially available immunoassay kits, such as DrugCheck K2/Spice Test, DrugSmart Cassette, and RapiCard InstaTest, have been developed for the detection of these drugs in urine. These devices are more useful than the colorimetric methods, because they do not require special reagents or tools, and the results are obtained easily and 
Indole 3-carbonylamide derivatives<smiles>[R]NC(=O)c1cn([R8])c2ccccc12</smiles>

\begin{tabular}{lll}
\hline & $\mathbf{R}_{\mathbf{1}}$ & $\mathbf{R}_{\mathbf{2}}$ \\
\hline APICA & $n$-Pentyl & Adamantyl \\
5F-APICA & 5-Fluoro- $n$-pentyl & Adamantyl \\
NNEI(MN-24) & $n$-Pentyl & 1-Naphthyl \\
5F-NNEI & 5-Fluoro- $n$-pentyl & 1-Naphthyl \\
\hline
\end{tabular}<smiles>[R]C(=O)C([R9])NC(=O)c1cn(Cc2ccccc2)c2ccccc12</smiles>

\begin{tabular}{llll}
\hline & $\mathbf{R}_{\mathbf{1}}$ & $\mathbf{R}_{\mathbf{2}}$ & $\mathbf{R}_{\mathbf{3}}$ \\
\hline ADBICA & $n$-Pentyl & $t$-Butyl & $\mathrm{NH}_{2}$ \\
PX1 & 5-Fluoro- $n$-pentyl & Benzyl & $\mathrm{NH}_{2}$ \\
\hline
\end{tabular}

Indole 3-carbonylester derivatives<smiles>[R]OC(=O)c1cn(Br)c2ccccc12</smiles>

\begin{tabular}{lll}
\hline & $\mathbf{R}_{\mathbf{1}}$ & $\mathbf{R}_{\mathbf{2}}$ \\
\hline NM-2201 & 5-Fluoro- $n$-pentyl & 1-Naphthyl \\
FDU-PB-22 & 4-Fluoro-benzyl & 1-Naphthyl \\
QUPIC(PB-22) & $n$-Pentyl & 8-Quinolinyl \\
5F-PB-22 & 5-Fluoro- $n$-pentyl & 8-Quinolinyl \\
QUCHIC(BB-22) & Cyclohexylmethyl & 8-Quinolinyl \\
FUB-PB-22 & 4-Fluoro-benzyl & 8-Quinolinyl \\
\hline
\end{tabular}

Fig. 1 continued

quickly. The devices also can detect older types of synthetic cannabinoids, such as JWH-018 or JWH-073, but, unfortunately, new designer drugs such as QUPIC and ABCHMINACA cannot be detected.

GC-MS detection

Typical mass spectra of synthetic cannabinoids are shown in Fig. 3. Molecular $\left(\mathrm{M}^{+}\right)$and/or fragment ions observed
Indazole 3-carbonylamide derivatives

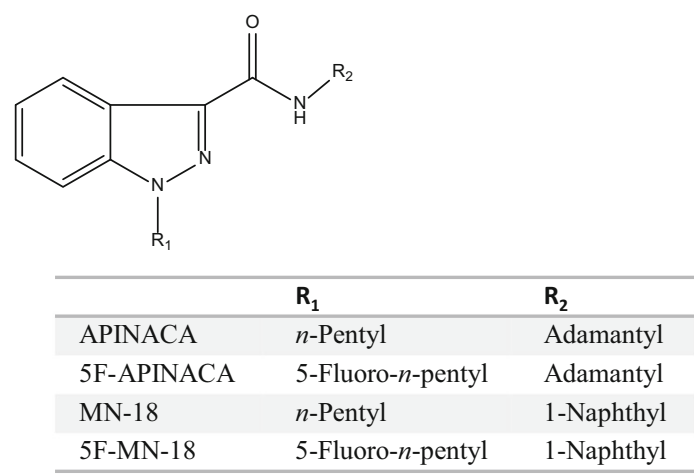<smiles>CC(NC(=O)c1nn(C)c2ccccc12)C(=O)O</smiles>

\begin{tabular}{llll}
\hline & $\mathbf{R}_{\mathbf{1}}$ & $\mathbf{R}_{\mathbf{2}}$ & $\mathbf{R}_{\mathbf{3}}$ \\
\hline AB-PINACA & $n$-Pentyl & $i$-Propyl & $\mathrm{NH}_{2}$ \\
5F-AB-PINACA & 5-Fluoro- $n$-pentyl & $i$-Propyl & $\mathrm{NH}_{2}$ \\
ADB-PINACA & $n$-Pentyl & $t$-Butyl & $\mathrm{NH}_{2}$ \\
AB-FUBINACA & 4-Fluoro-benzyl & $i$-Propyl & $\mathrm{NH}_{2}$ \\
ADB-FUBINACA & 4-Fluoro-benzyl & $t$-Butyl & $\mathrm{NH}_{2}$ \\
AB-CHMINACA & Cyclohexylmethyl & $i$-Propyl & $\mathrm{NH}_{2}$ \\
AMB & $n$-Pentyl & $i$-Propyl & Methoxy \\
5F-AMB & 5-Fluoro- $n$-pentyl & $i$-Propyl & Methoxy \\
\hline
\end{tabular}

Indazole 3-carbonylester derivatives<smiles>COC(=O)c1nn(C)c2ccccc12</smiles>

\begin{tabular}{lll}
\hline & $\mathbf{R}_{\mathbf{1}}$ & $\mathbf{R}_{\mathbf{2}}$ \\
\hline 5F-SDB-005 & 5-Fluoro- $n$-pentyl & 1-Naphthyl \\
5F-NPB-22 & 5-Fluoro- $n$-pentyl & 8-Quinolinyl \\
\hline
\end{tabular}

by full scan data acquisition of GC-MS reflect the structures of the synthetic cannabinoids [13, 15, 16]. As shown in Fig. 4, the fragmentation pathways of naphthoylindoles have been well studied for the identification of synthetic cannabinoids by GC-MS $[12,15]$. Therefore, the identification of synthetic cannabinoids is facilitated by comparison of the spectra with commercial and open databases.

In naphthoylindoles, the carbonyl group fragment ions, which are caused by $\alpha$-cleavage of the alkylamino group of 
<smiles>[R]c1ccc(C(=O)C([R])N([R])[R])cc1[R]</smiles>

\begin{tabular}{lllllc}
\hline Name & $\mathbf{R}_{\mathbf{1}}$ & $\mathbf{R}_{\mathbf{2}}$ & $\mathbf{R}_{\mathbf{3}}$ & $\mathbf{R}_{\mathbf{4}}$ & $\mathbf{R}_{\mathbf{5}}$ \\
\hline Cathinone & Methyl & $\mathrm{H}$ & $\mathrm{H}$ & $\mathrm{H}$ & $\mathrm{H}$ \\
Methcathinone & Methyl & Methyl & $\mathrm{H}$ & $\mathrm{H}$ & $\mathrm{H}$ \\
$N, N$-Dimethylcathinone & Methyl & Methyl & Methyl & $\mathrm{H}$ & $\mathrm{H}$ \\
Mephedrone & Methyl & Methyl & $\mathrm{H}$ & Methyl & $\mathrm{H}$ \\
3,4-Dimethylmethcathinone & Methyl & Methyl & $\mathrm{H}$ & Methyl & Methyl \\
4-Ethylmethcathinone & Methyl & Methyl & $\mathrm{H}$ & Ethyl & $\mathrm{H}$ \\
Methylone & Methyl & Methyl & $\mathrm{H}$ & Methylenedioxy \\
\hline Ethcathinone & Methyl & Ethyl & $\mathrm{H}$ & $\mathrm{H}$ & $\mathrm{H}$ \\
\hline Ethylone & Methyl & Ethyl & $\mathrm{H}$ & Methylenedioxy \\
Amfepramone & Methyl & Ethyl & $\mathrm{Ethyl}$ & $\mathrm{H}$ & $\mathrm{H}$ \\
Buphedrone & Ethyl & Methyl & $\mathrm{H}$ & $\mathrm{H}$ & $\mathrm{H}$ \\
4-Methylbuphedrone & Ethyl & Methyl & $\mathrm{H}$ & Methyl & $\mathrm{H}$ \\
\hline Butylone & Ethyl & Methyl & $\mathrm{H}$ & Methylenedioxy \\
$N$-Ethylbuphedrone & Ethyl & Ethyl & $\mathrm{H}$ & $\mathrm{H}$ & $\mathrm{H}$ \\
\hline Eutylone & Ethyl & Ethyl & $\mathrm{H}$ & Methylenedioxy \\
\hline Pentedrone & Propyl & Methyl & $\mathrm{H}$ & $\mathrm{H}$ & $\mathrm{H}$ \\
$\alpha$-Ethylaminopentiophenone & Propyl & Ethyl & $\mathrm{H}$ & $\mathrm{H}$ & $\mathrm{H}$ \\
\hline & & & & \multicolumn{2}{c}{} \\
\hline
\end{tabular}

Fig. 2 Structures of cathinones

the indole, are typically observed. In addition, $[\mathrm{M}-17]^{+}$is certainly observed in naphthoylindoles. For example, fragment ions at $\mathrm{m} / \mathrm{z} 284$ and 214 are observed in JWH018 , corresponding to those of the indole moiety caused by $\alpha$-cleavage of the $N$-pentyl of indole and naphthoyl. Fragment ions at $\mathrm{m} / \mathrm{z}, 127$ and 155 are observed in JWH018 , corresponding to the naphthalene group caused by the $\alpha$-cleavage of the carbonyl group. Moreover, ions at $\mathrm{m} / \mathrm{z} 324$ are observed as $[\mathrm{M}-17]^{+}$(Fig. 3a). Like naphthoylindoles, fragment ions caused by $\alpha$-cleavage of the alkylamino group of the indole and carbonyl groups are shown, although $[\mathrm{M}-17]^{+}$is not observed for benzoylindoles. For example, fragment ions at $m / z, 264$ and 214 are observed for RCS-4, caused by $\alpha$-cleavage of $N$-pentyl of the indole and 4-methoxybenzoyl. The ions at $\mathrm{m} / \mathrm{z} 127$ and 155 , which are caused by naphthyl and naphthoyl moieties of naphthoylindoles (Fig. 3a), and the ion at $\mathrm{m} / \mathrm{z} 135$ caused by the 4-methoxybenzoyl moiety (Fig. 3b) are useful as precursor ions for identification of these drugs by GC-MS-MS. On the other hand, the methylpiperidine moiety is bound to the nitrogen of the indole, and the ion at $\mathrm{m} / \mathrm{z} 98$ is observed as the base peak (Fig. 3d). Unlike naphthoyl and benzoyl indoles, the base peak of the

\begin{tabular}{|c|c|c|c|}
\hline Name & $\mathrm{R}_{1}$ & $\mathbf{R}_{2}$ & $\mathbf{R}_{3}$ \\
\hline$\alpha$-PРP & Methyl & $\mathrm{H}$ & $\mathrm{H}$ \\
\hline$\alpha-$-PBP & Ethyl & $\mathrm{H}$ & $\mathrm{H}$ \\
\hline$\alpha-P V P$ & Propyl & $\mathrm{H}$ & $\mathrm{H}$ \\
\hline$\alpha$-PHP & Butyl & $\mathrm{H}$ & $\mathrm{H}$ \\
\hline PV8 & Pentyl & $\mathrm{H}$ & $\mathrm{H}$ \\
\hline PV9 & Hexyl & $\mathrm{H}$ & $\mathrm{H}$ \\
\hline МРPP & Methyl & Methyl & $\mathrm{H}$ \\
\hline МOPРP & Methyl & Methoxy & $\mathrm{H}$ \\
\hline MPBP & Ethyl & Methyl & $\mathrm{H}$ \\
\hline Pyrovalerone & Propyl & Methyl & $\mathrm{H}$ \\
\hline Naphyrone & Propyl & Phenyl & \\
\hline MPHP & Butyl & Methyl & $\mathrm{H}$ \\
\hline MDPPP & Methyl & \multicolumn{2}{|c|}{ Methylenedioxy } \\
\hline MDPBP & Ethyl & \multicolumn{2}{|c|}{ Methylenedioxy } \\
\hline MDPV & Propyl & \multicolumn{2}{|c|}{ Methylenedioxy } \\
\hline
\end{tabular}<smiles>[R]c1ccc(C(=O)C([R7])N2CCCC2)cc1[R]</smiles>

fragment ion caused by the $\mathrm{N}$-alkylindole 3-carbonyl moiety for phenylacetyl (Fig. 3c), cyclopropyl, or adamantyl (Fig. 3f) indoles, is only shown in each full scan spectrum. Analogs, in which the indole skeleton is changed to an indazole, such as THJ-018, have also appeared on the market. In these analogs, molecular and $N$-dealkylated ions are typically observed in the spectrum (Fig. 3e).

Recently, amide- or ester-type analogs bonded with an $\mathrm{N}$ alkylindole or $\mathrm{N}$-alkylindazole 3-carbonyl moiety have appeared on the market $[17,18]$. In these analogs, the abundance of the molecular ion is low, and the fragment ion caused by the indoyl (or indazoyl) moiety is observed as a base peak (Fig. 3f-k). Although the fragment ion caused by elimination of the terminal CO- $\mathrm{NH}_{2}$ is lower than that of the cleavage of the amide moiety in indole analogs, such as ADBICA (Fig. 3h) [19], the fragment ion caused by elimination of terminal $\mathrm{CO}-\mathrm{NH}_{2}$ is as intense as that of the cleavage of the amide moiety in indazole analogs, such as ADB-PINACA and AB-CHMINACA (Fig. 3j, k) [20]. The substitution of the indole skeleton with the indazole moiety, such as in THJ-018 and THJ-2201 [21], has also been observed in these analogs. In these analogs, molecular and $N$ dealkylated ions are typically observed in the spectrum. 
(a)

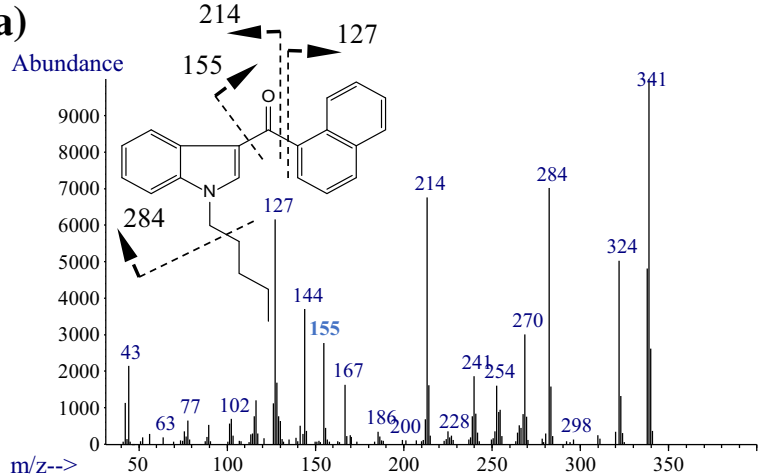

(c)

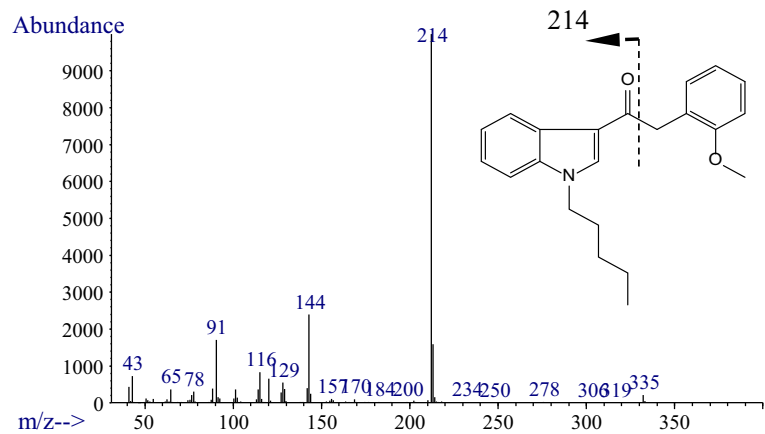

(d)

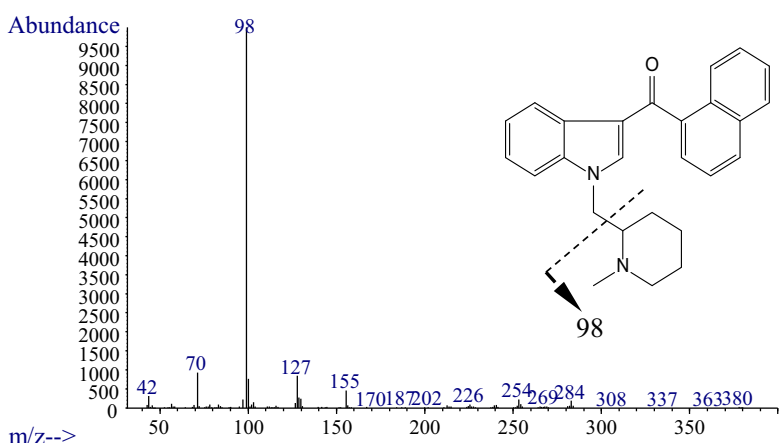

(b)

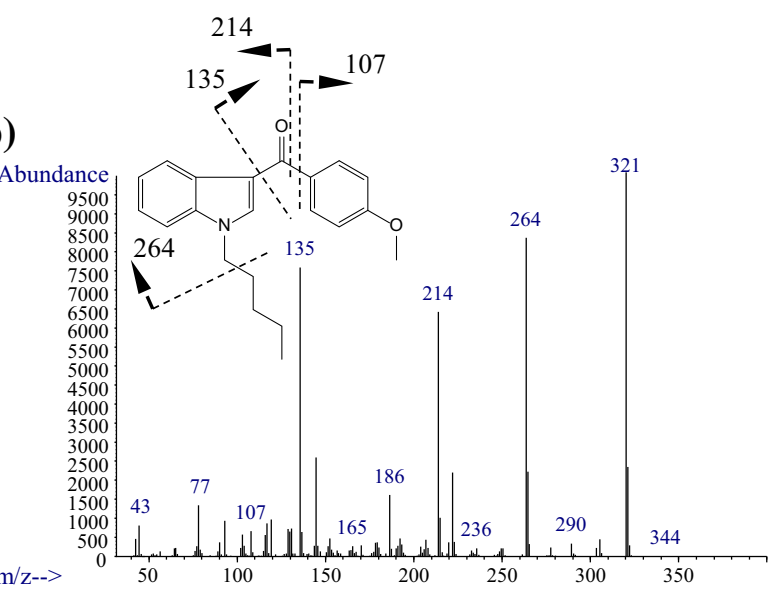

(e)

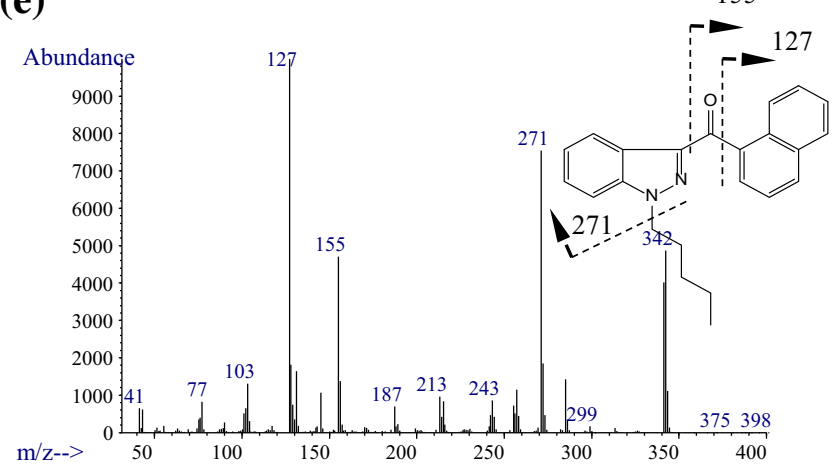

Fig. 3 Typical mass spectra of synthetic cannabinoids obtained by GC-MS. a JWH-018, b RCS-4, c JWH-250, d AM-1220, e THJ-018, f APICA, g NNEI, h ADBICA, i QUPIC (PB-22), j ADB-PINACA, k AB-CHMINACA

For example, in the simultaneous analysis of synthetic cannabinoid species, $10 \mathrm{mg}$ of ground powder of the dried leaves was extracted with $10 \mathrm{ml}$ of methanol under ultrasonication for $10 \mathrm{~min}$. The extracts were centrifuged for $5 \mathrm{~min}$ at 3,000 rpm, and the supernatants were filtered and used for GC-MS analysis. The LODs were $0.5-1.0 \mathrm{mg} / \mathrm{l}$, and linearity was obtained at concentrations up to $100 \mathrm{mg} / \mathrm{l}[16]$. In another article [22], herbal samples (approximately $50 \mathrm{mg}$ ) were put into $10-\mathrm{ml}$ headspace vials, and the vials were capped with 20-mm magnetic crimp seal caps with $\mathrm{PTFE} /$ silicone septa. The samples were incubated at $200{ }^{\circ} \mathrm{C}$ with pulse-agitation at $250 \mathrm{rpm}$. A StableFlex carboxen/ polydimethylsiloxane fiber was inserted into the headspace for $5 \mathrm{~min}$ for extraction. The fiber was then injected into the GC inlet for 15 min to desorb the analytes. The LOD of synthetic cannabinoid in the samples was at least $20 \mu \mathrm{g}$.

The tentative identification of synthetic cannabinoids appears easy, but similar mass spectra are sometimes obtained by GC-MS because regio- and ring-substituted analogs are still distributed on the market. The misidentification of these analogs arises when using only the information from the mass spectra. When tandem and high-resolution MS are 
(f)

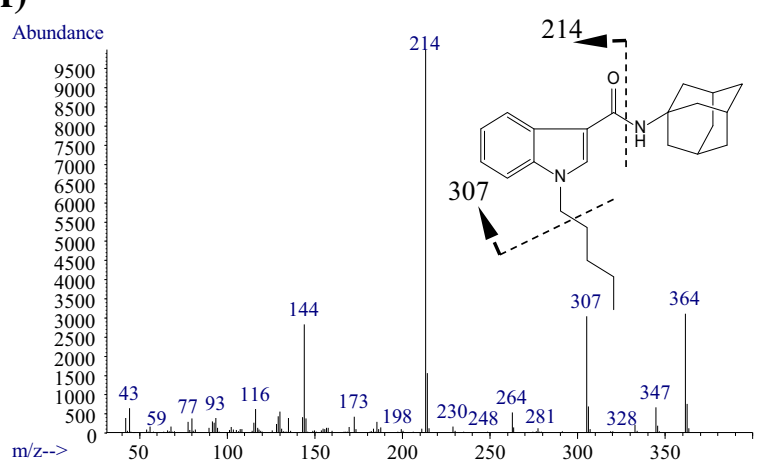

(h)
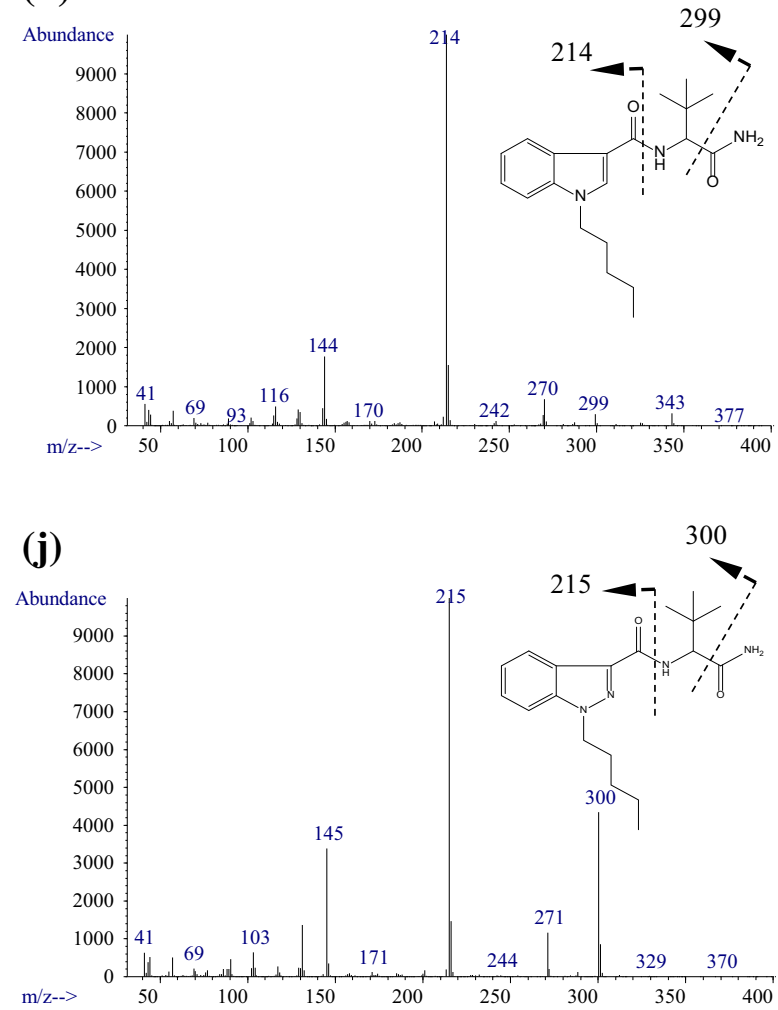

Fig. 3 continued

used to identify the conformational isomers or regioisomers, such misidentification does not occur [23-28]. Moreover, identification of cyclopropyl or ester analogs, such as UR144 or QUPIC, is usually not possible because cyclopropyl analogs are heat-unstable and are easily degraded in the injection port of the GC instrument [29, 30].

\section{LC-MS-MS detection}

Many research groups have used LC-MS-MS for determination of synthetic cannabinoids in herbs and biological samples, and some have studied the fragmentation of (g)

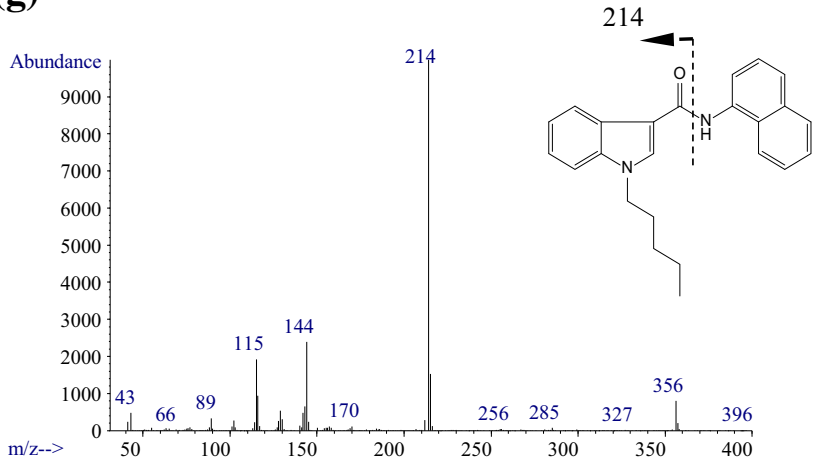

(i)

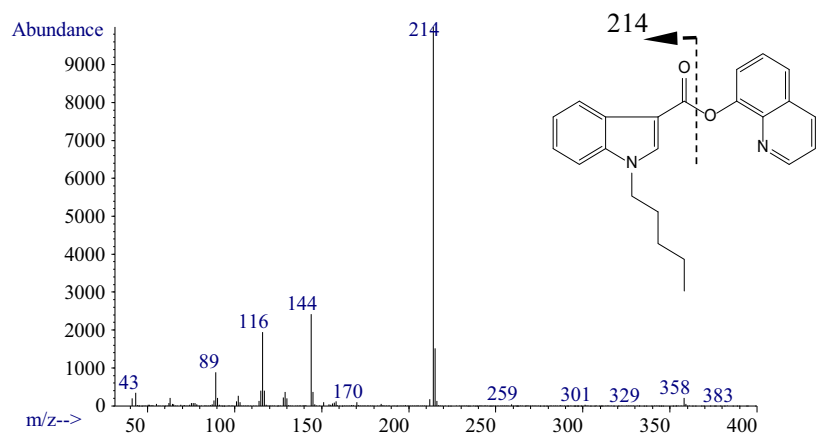

(k)

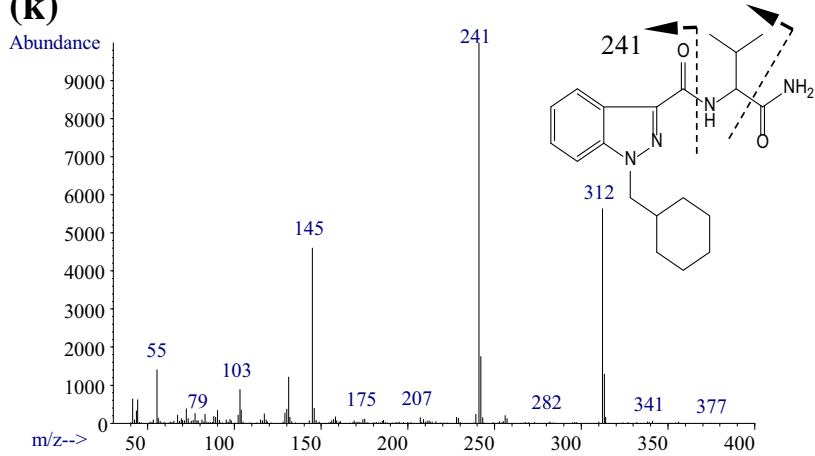

synthetic cannabinoids in detail $[15,31]$. The probable fragmentation pathways are shown in Fig. 4. Because the protonated molecular ion is only observed by LC-MS, and the information acquired by LC-MS is lesser than that for GC-MS, it is necessary to obtain other data that reflect the chemical structures by LC-MS-MS or TOFMS. Fragment ions are observed by product ion scanning when the protonated molecular ion is used as the precursor ion. In naphthoylindole, ions at $\mathrm{m} / \mathrm{z} 127$ and 155 are generated by naphthyl and naphthoyl moieties. However, information about the indole moiety tends to be not revealed by LCMS-MS. On the other hand, the $N$-alkyl moiety of a 


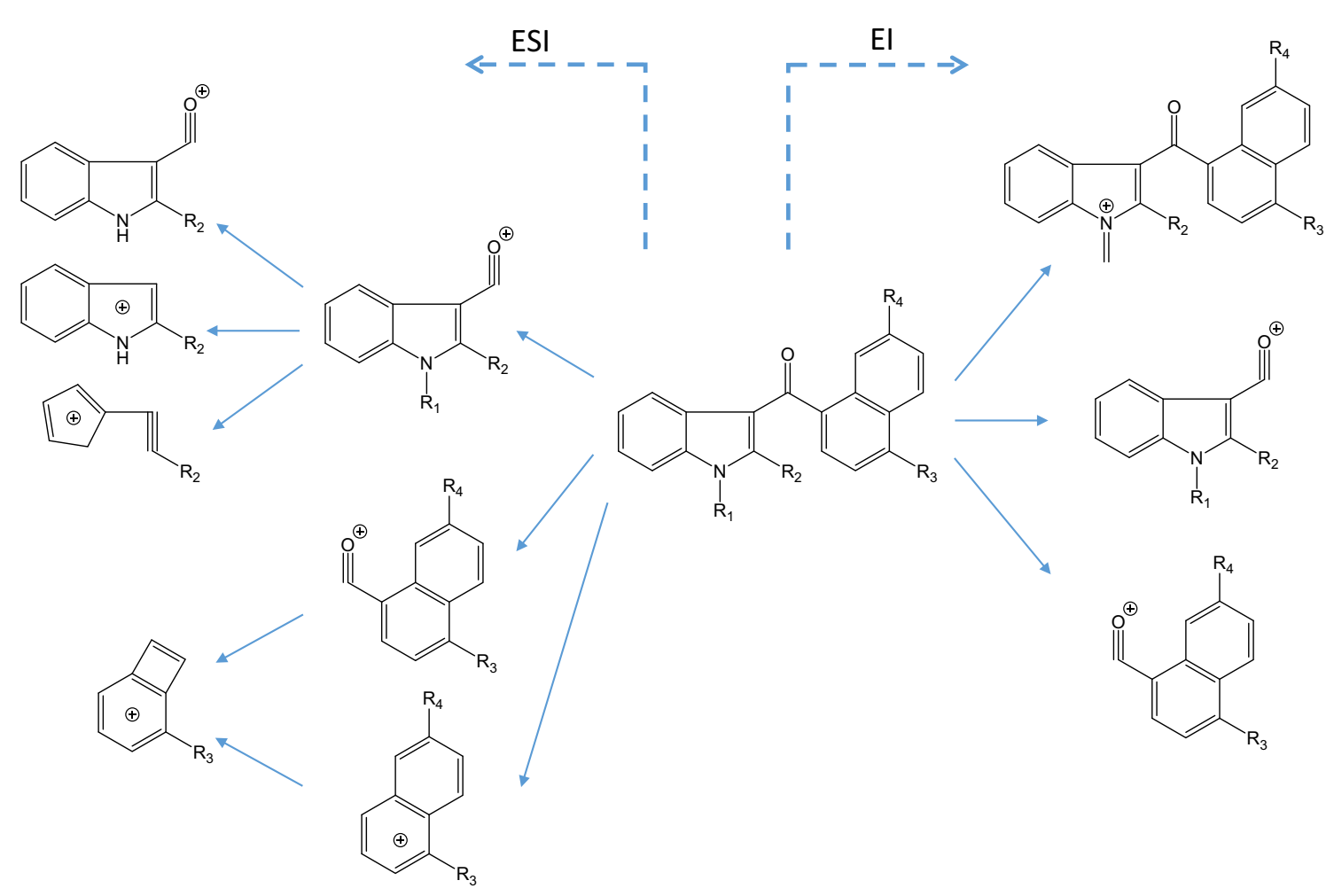

Fig. 4 Probable fragmentation pathways of synthetic cannabinoids by electrospray ionization and electron ionization (modified from references $[12,31])$

synthetic cannabinoid is mainly modified for excretion into urine as a metabolite. Therefore, LC-MS-MS is a useful methodology to search for metabolites of synthetic cannabinoids in urine.

Recently, packages containing mixtures of multiple synthetic cannabinoids have been sold commercially, even though the package ingredients have been largely unknown to both sellers and buyers. In this aspect, the LC-MS-MS screening method is helpful in some estimation of the ingredients. Kneisel and Auwärter [32] demonstrated the simultaneous detection of 30 synthetic cannabinoids in serum; the LODs and LOQs were $0.01-2.0$ and $0.1-2.0 \mathrm{ng} /$ $\mathrm{ml}$, respectively. There are many applications for analysis of synthetic cannabinoids in urine, hair, and oral fluids [3337]. The typical published methods for analysis of synthetic cannabinoids in biological materials are summarized in Table 1 [38-54]. Simple LLE is usually used for the extraction of synthetic cannabinoids from biological materials because of the high hydrophobicity of the drugs. The chromatographic conditions are generally simple and do not require a special technique; octadecyl-type columns were used as analytical columns and analyses were performed in gradient mode.

The identification of an unknown drug in a biological material without information is almost always difficult, even if analysis is carried out with LC-MS-MS. To overcome this situation, high-resolution MS or TOFMS become helpful tools for tentative estimation of parent drugs and their metabolites of synthetic cannabinoids.

To clarify the chemical structure of an unknown drug in a herbal blend product that contains more than several milligrams of the drug, GC-MS, LC-MS-MS, and highresolution MS (or TOFMS) can be used to estimate the structure. The target compound is then purified by preparative LC or preparative TLC to obtain more than several milligrams of the compound of high purity, which is then analyzed by NMR spectroscopy [17-21]. The detailed chemical structure can be elucidated by the above laborious instrumental analyses.

\section{Cathinones}

Colorimetric detection

The Marquis reagent, which reacts with all nitrogen-containing drugs, is negative for cathinones, such as cathinone and mephedrone, but is positive for cathinone analogs that have a methylenedioxy moiety in each molecule. The cathinone analogs with a methylenedioxy moiety also react with the Chen reagent, which changes to orange in positive tests. Although the LOD concentration is not reported, the 


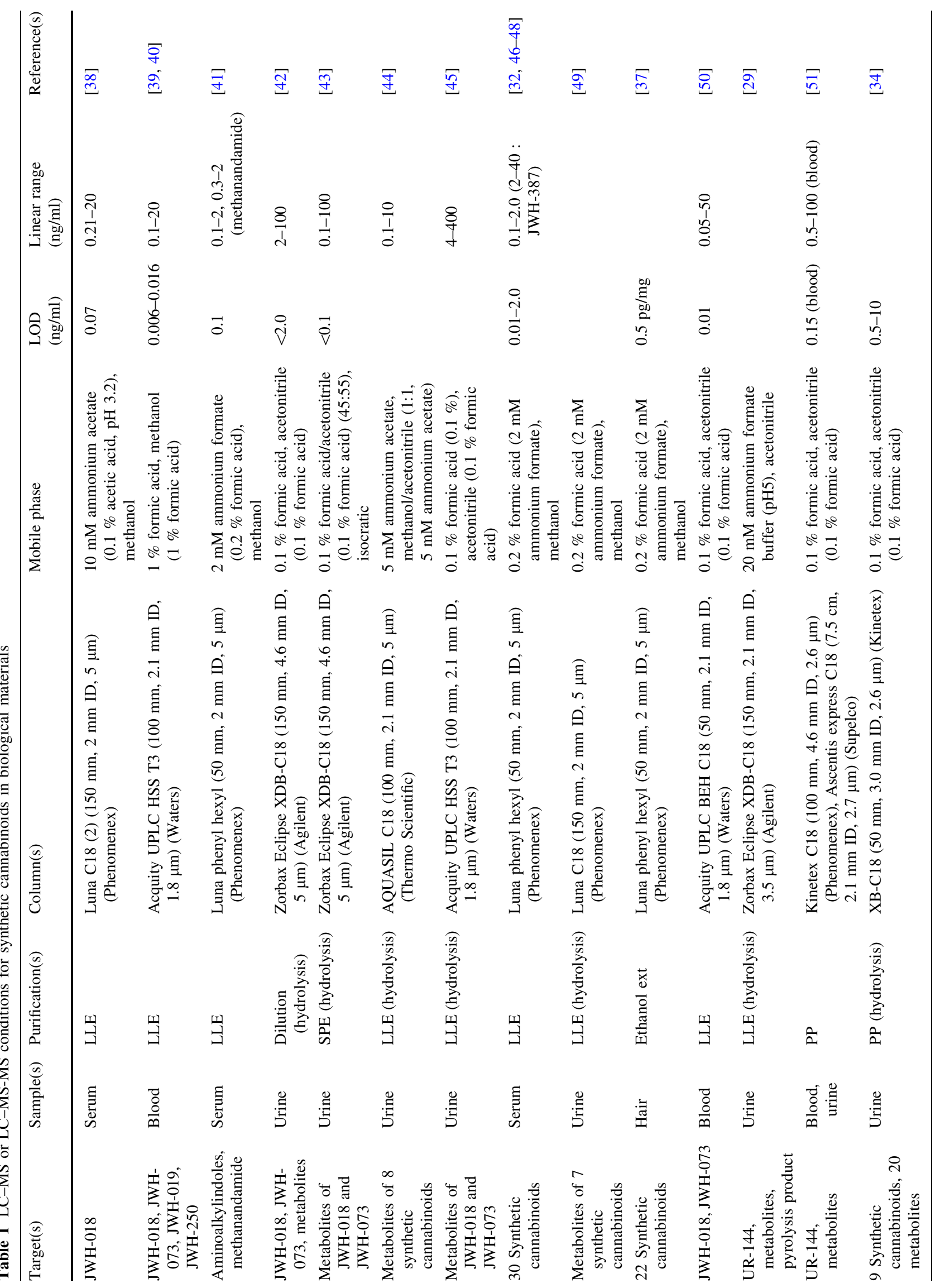




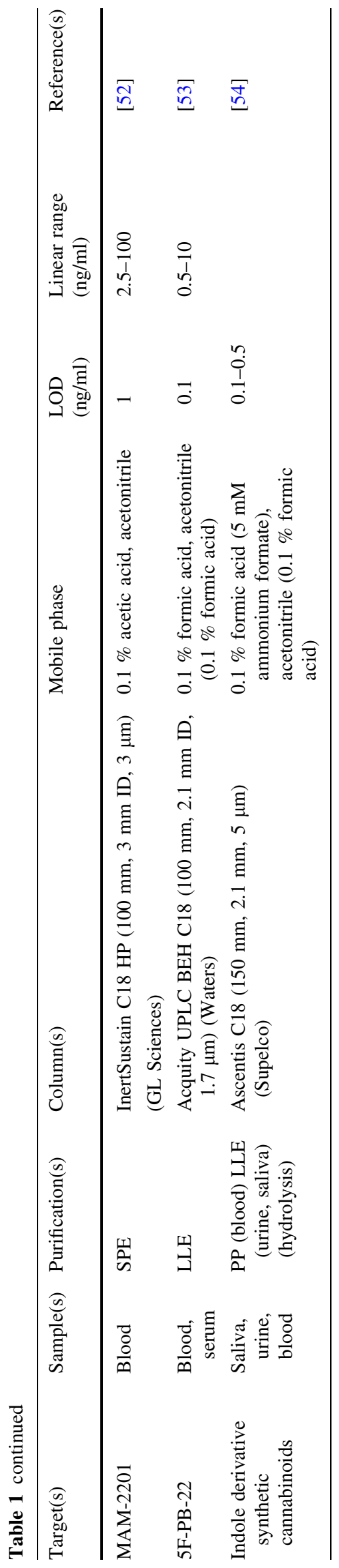

described test solution contained cathinone powder (at least $10 \mathrm{mg})$ suspended in methanol $(1 \mathrm{ml})$ [55-57]. The combination of Marquis, Ehrlich, Simon, LiebermanBurehand, and Mandelin reagents is useful for the detection of cathinones in samples. Like synthetic cannabinoids, the identification of these compounds, of course, cannot be performed using these methods; moreover, the detection of small amounts or mixtures of cathinones is difficult.

Immunochemical detection

Some researchers have tried to detect cathinones in urine using immunoassay technology [58, 59]. Some articles revealed false-positive results by immunoassays; for example, MDPV was cross-reactive with phencyclidine [60]. Therefore, specific detection of cathinones by a commercial immunoassay is not yet possible.

GC-MS-MS detection

Mass spectral profiles of cathinones are very simple in the positive mode of GC-MS, because only the base peak originating from the immonium ion in each molecule is observed. The probable fragmentation pathways of cathinones are described in previous articles [61-64] and are shown in Fig. 5. However, this phenomenon makes the identification of cathinones difficult. To help identify cathinones, other information, such as tandem mass spectrometric data, are usually used because more structural information about the molecule is obtained.

Zuba [61] introduced the systematic identification of cathinones using the mass spectra obtained. First, it should be checked whether the molecular ion is observed. The immonium ion $(m / z=16+14 n, n=1,2,3, \ldots)$ is then checked in the EI spectrum. If the immonium ion is found in the spectrum, the substance could be a straight-chained cathinone. If not, it is checked whether the ion for a pyrrolidine ring is observed $(m / z=70+14 n, n=1,2$, $3, \ldots$ ). If this ion is found in the spectrum, the substance could be a cathinone with a pyrrolidine ring in the molecule [61]. There are various regioisomers in cathinones. To identify the cathinones, it is necessary to assign both the location and length of the bonded alkyl chain. Moreover, the ring-substituted moiety is also needed to be assigned. Zuba [61] demonstrated the following rules: the fragment ions reflecting the ring-substituted moiety are observed at $\mathrm{m} / \mathrm{z}, 77$ and 105 for a nonsubstituted phenyl ring, at $\mathrm{m} / \mathrm{z}, 91$ and 119 for a methylphenyl ring, and at $\mathrm{m} / z, 121$ and 149 for a methylenedioxyphenyl ring. Matsuta et al. [62] demonstrated the detailed analysis of MS data obtained by GC-EI-MS for identification of cathinones and specified indexing information. However, the ionization rate of the fragments in ring-substituted cathinones is remarkably 


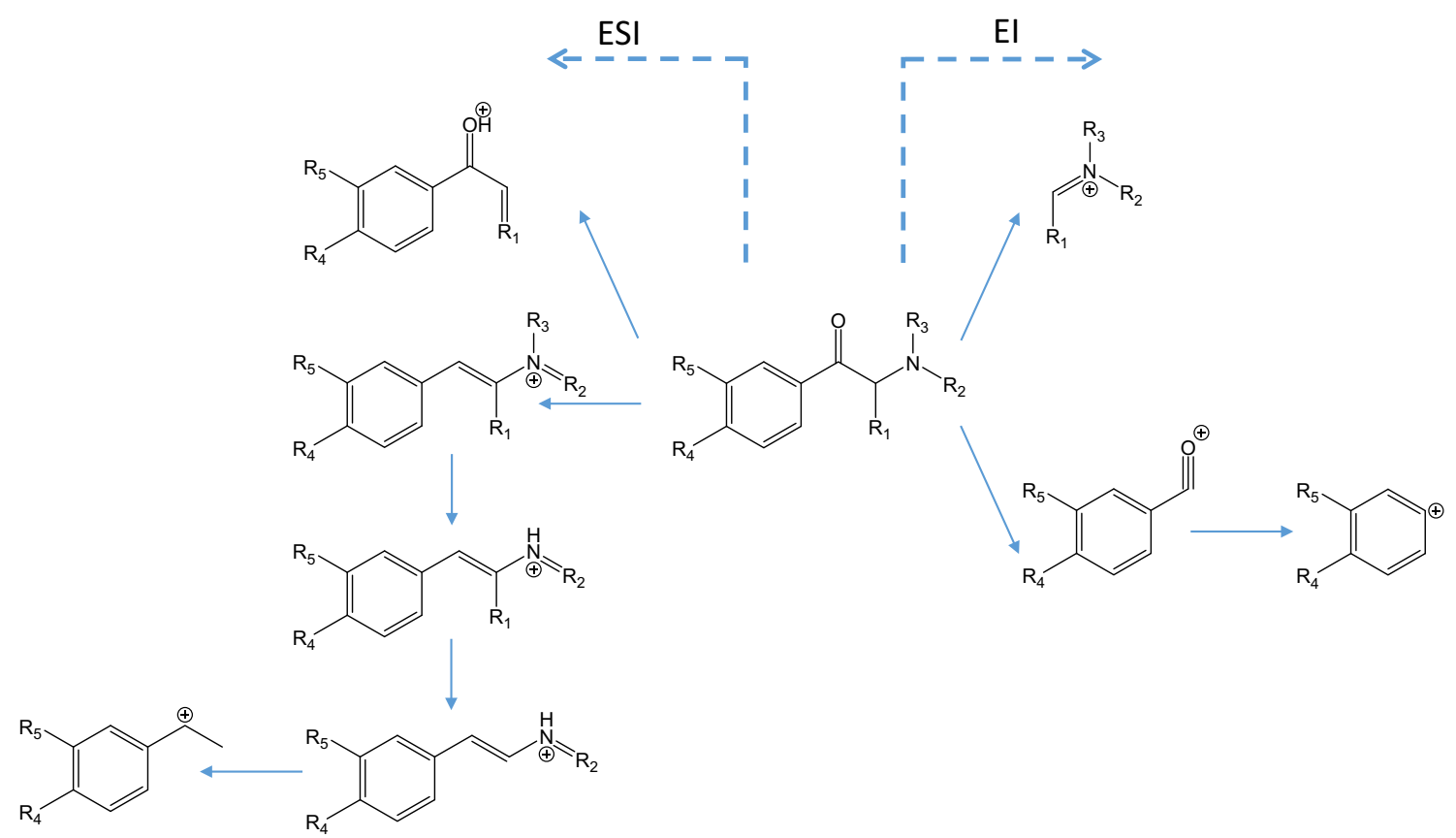

Fig. 5 Probable fragmentation pathways of cathinones by electrospray ionization and electron ionization (modified from references [61, 62, 65, 66])

weaker than that of the immonium ion. Other information obtained by TOFMS or CI-MS is helpful to delineate the molecular structure [63-66]. The identification of the regioisomer of the fluorinated cathinones was demonstrated using CI-MS [67]. However, this phenomenon was suggested to be limited to these analogs.

The published methods for analysis of cathinones in biological materials are summarized in Table 2 [68-79]. Simple LLE is usually used for extraction of cathinones from biological materials. The chromatographic conditions are also simple and do not usually require a special technique.

\section{LC-MS-MS detection}

The strategy for the detection of cathinones by LC-MS-MS is almost same as that for synthetic cannabinoids; almost all methods use MRM or SRM mode for sensitive determination. The probable fragmentation pathways are shown in Fig. 5. The $[\mathrm{M}+\mathrm{H}]^{+}$ion is selected as a precursor ion, and three product ions that reflect the chemical structures of the cathinones are selected. Using this method, 30-50 drugs are monitored simultaneously in samples [80-82]. The published methods for analysis of cathinones in biological materials are summarized in Table $3[68,69,74$, 75, 77, 79, 82-98]. Simple LLE is usually used for the extraction of cathinones from biological materials. The chromatographic conditions are also simple and do not require a special technique.

In the same way as identification by GC-MS, other information obtained by TOFMS or tandem MS is needed to clarify the molecular structure. An authentic drug or library database is needed to identify the drugs. Moreover, the probable fragmentation pathways of cathinones are described in the previous articles $[61,65,66,99]$. These data are helpful in identifying the drugs.

As described in the section on synthetic cannabinoids, we occasionally encounter a dubious product that contains more than several milligrams of an unknown cathinone-like compound. In such a case, GC-MS, LC-MS, high-resolution MS (or TOFMS), and finally NMR spectroscopy are used to clarify the detailed chemical structure of the compound.

\section{Concentrations in the cases of abuse}

Synthetic cannabinoids

The common method of consumption of synthetic cannabinoids is smoking, which is the same as for conventional cannabis. The maximum concentrations of synthetic cannabinoids in serum are reached in less than 10 min after smoking [38]. The drugs absorbed in the body are metabolized smoothly, and the concentrations decrease rapidly. Moreover, there is also a report that cannabinoids accumulate in the adipose tissue because of their high lipophilicity [52]. Therefore, detection of the drug from serum is usually difficult. Synthetic cannabinoids absorbed in the human body are metabolized to hydroxyl or carboxyl derivatives of the aromatic ring or $N$-alkyl side chain [100]. It is difficult to identify the parent drug and its metabolites 


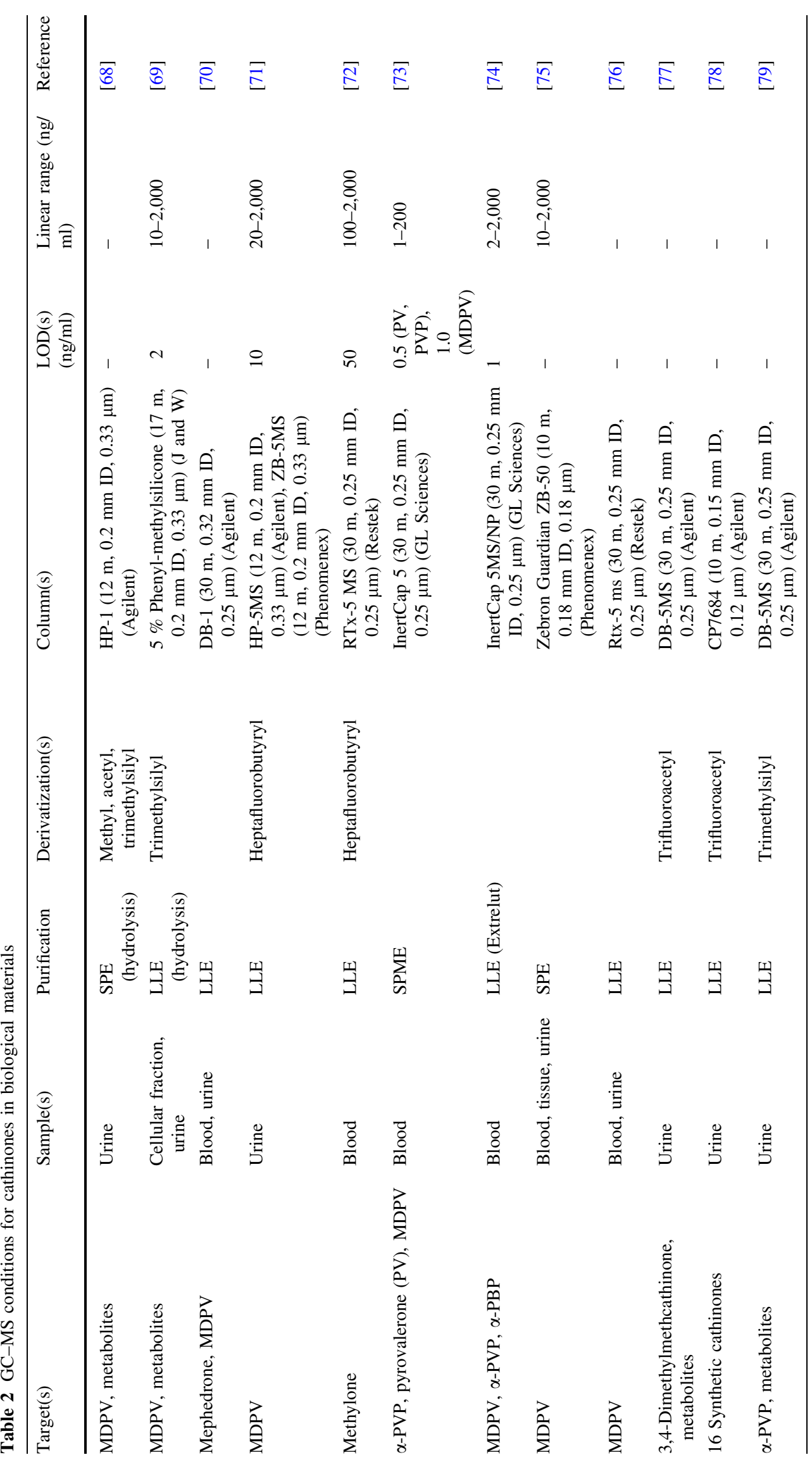




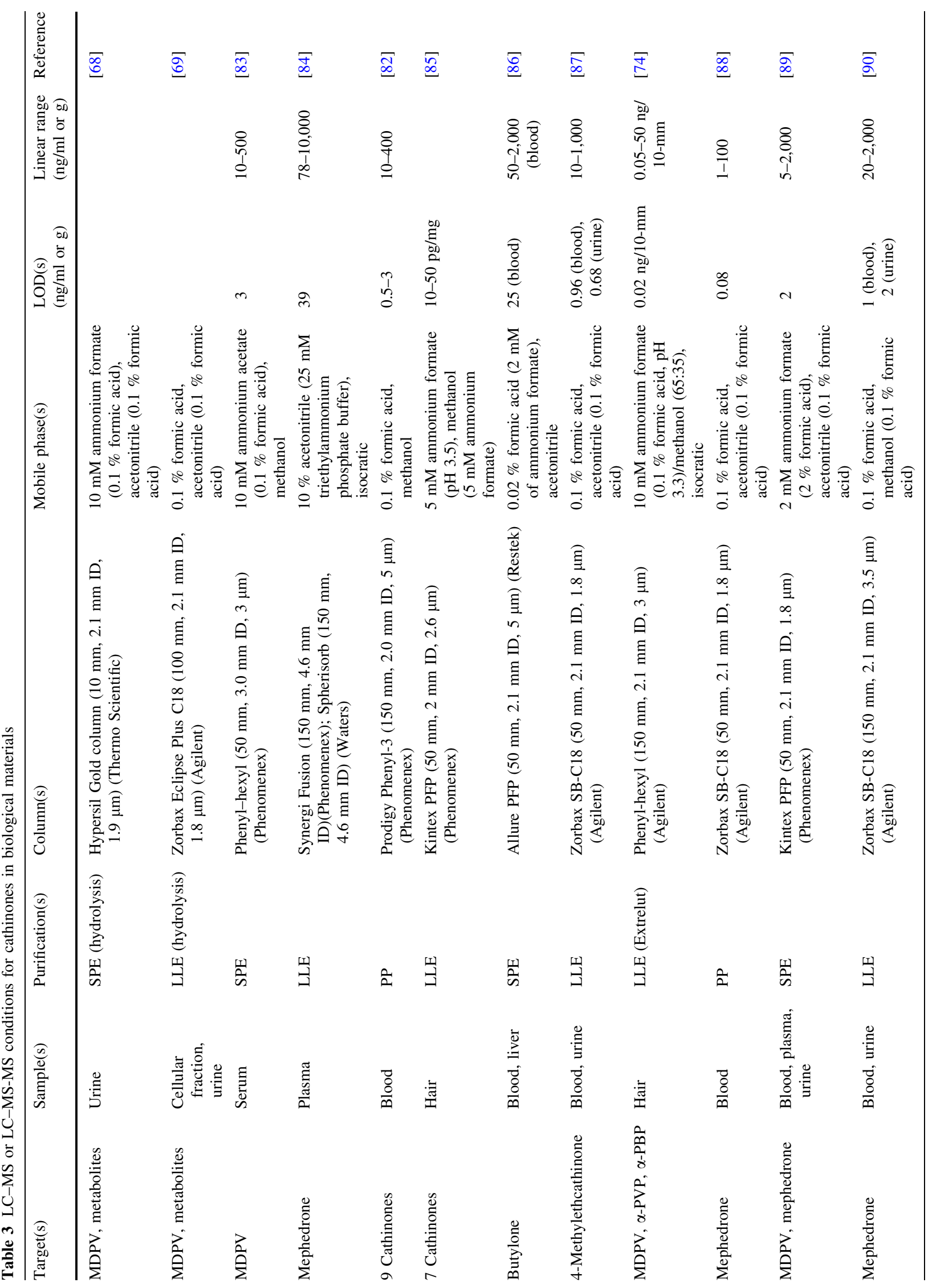




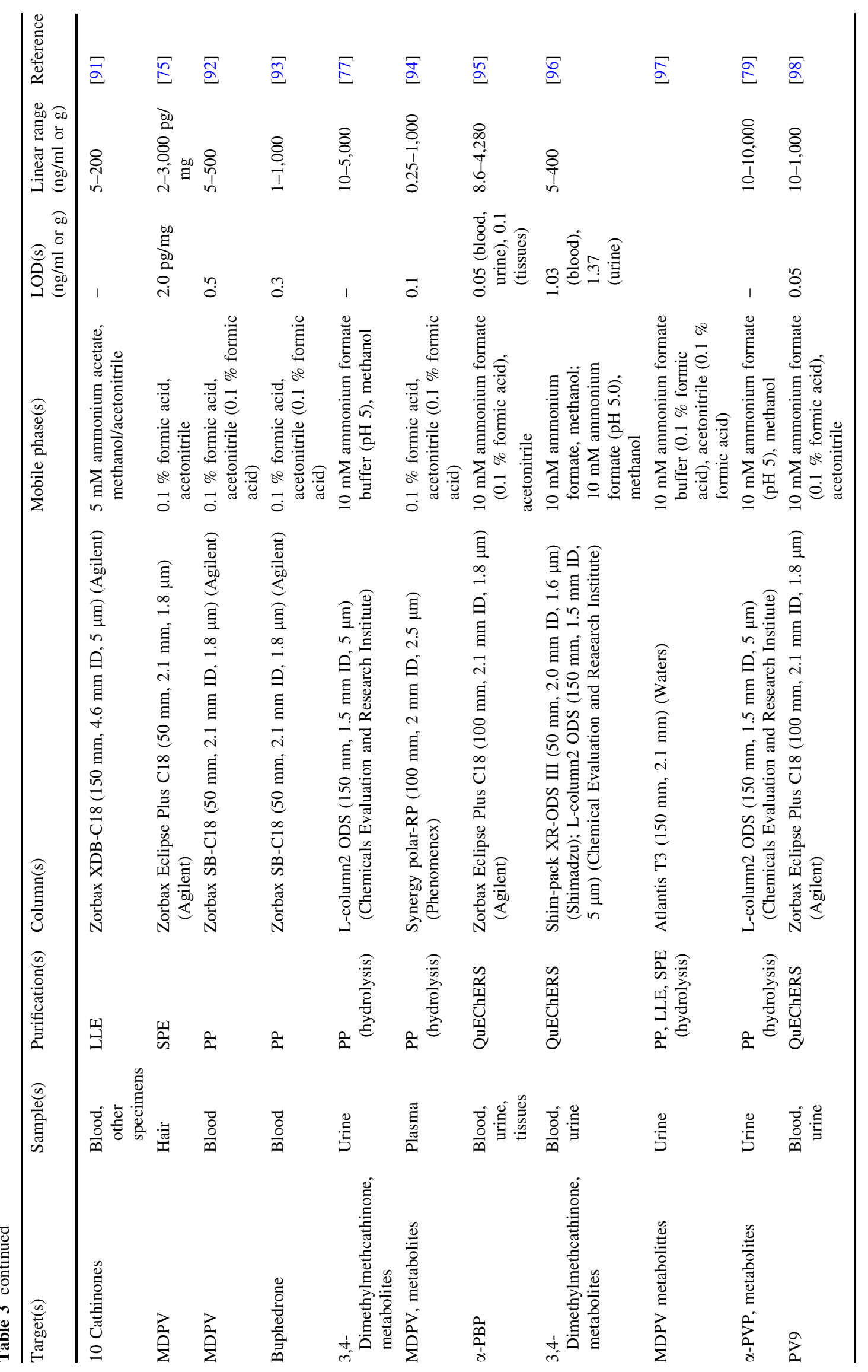


in blood by GC-MS alone because the fragmentation of the metabolites is similar to that of the parent drug and analogs. Moreover, the concentration of the unchanged synthetic cannabinoids in blood is very low, and the number of metabolites that are commercially available is small. Low sensitivity is a limitation for the determination of synthetic cannabinoids in blood by GC-MS.

Although the concentration is influenced by the sampling time after drug intake and by the intake amount, concentrations of these drugs in serum were reported in the range of $0.1-190 \mathrm{ng} / \mathrm{ml}$ in poisoning cases [46]. In fatal cases, the concentrations of the drugs in blood were $0.1-199 \mathrm{ng} / \mathrm{ml}$ for JWH-018 and $0.1-68.3 \mathrm{ng} / \mathrm{ml}$ for JWH073 [50], $12 \mathrm{ng} / \mathrm{ml}$ for AM-2201 [100], 1.1-1.5 ng/ml for 5F-PB-22 [53], and $12.4 \mathrm{ng} / \mathrm{ml}$ for MAM-2201 [52].

\section{Cathinones}

Unlike synthetic cannabinoids, the most common method of consumption of cathinones are insufflation (snorting) or ingestion. Inhalation, sublingual and rectal administration, and intramuscular or intravenous injection have also been reported. Unlike synthetic cannabinoids, the concentration of cathinones in blood is thought to vary because of the many modes of administration used by abusers. Only the blood concentration at one point and at several points have been quantified, and there is no report on continuous monitoring of the profile of the drug concentration in blood. The fatal concentration of the drug in blood was reported to be around $400 \mathrm{ng} / \mathrm{ml} \mathrm{[75].} \mathrm{The} \mathrm{stability} \mathrm{of}$ cathinones in blood samples is clearly influenced by $\mathrm{pH}$, as well as in the final extracts. In blood samples preserved with $\mathrm{NaF} /$ potassium oxalate, the measured concentrations of cathinone, methcathinone, ethcathinone, mephedrone, and flephedrone declined by ca. $30 \%$ after 2 days of storage at $20{ }^{\circ} \mathrm{C}$ [82].

Some groups have studied the metabolic pathways of cathinones [68, 94, 101-103]. Unlike synthetic cannabinoids, the parent cathinones are detected easily in biological materials and are selected as the target because the unchanged parent drugs are rapidly excreted in urine. Cathinones are ionized in the body, and the reabsorption rate is low in the kidney because of low hydrophobicity. The excretion profile of $\alpha$-PBP and $\alpha$-PVP in human urine was determined after an intravenous injection, and the elimination half-life in urine was approximately $12 \mathrm{~h}$. Moreover, the excreted amount in urine was influenced by urinary $\mathrm{pH}$, like a psycho-stimulant [104]. To analyze these drugs in biological materials, it is necessary to remove endogenous substances from each sample and enrich the content of the drug. As shown in Table 3, LLE is usually used for extraction of the drugs from biological materials. The quantification of the metabolites is important to predict the hazardous properties of the metabolites. However, because there are few metabolites marketed, no detailed study about their pharmacological activity or toxicity has been conducted.

In fatal cases, the concentrations of the drugs in blood were: $560-3,300$ [72], 272 [105], and $60-1,120 \mathrm{ng} / \mathrm{ml}$ [106] for methylone; 1.2-22 [107], 5.1 [108], and $5.5 \mu \mathrm{g} /$ $\mathrm{ml}$ [88] for mephedrone; $55.2 \mathrm{ng} / \mathrm{ml}$ for $\alpha$-PBP [95]; 486 [73] and $654 \mathrm{ng} / \mathrm{ml}$ [109] for $\alpha-P V P ; 180 \mathrm{ng} / \mathrm{ml}$ [98] for PV9; 170 [70], 82 [110], 1,200 [74], 440 [75], 17-38 [92], and $700 \mathrm{ng} / \mathrm{ml}[111]$ for MDPV.

\section{Conclusions}

The number of abusers of synthetic cannabinoids and cathinones has increased remarkably worldwide. The chemical structures of the distributed drugs are skillfully changed so that the drugs may pass through screenings for detection. Simple screening methods are required for detection of these drugs in seized and biological materials. There are currently no commercial kits or devices for the routine screening of these drugs. Colorimetric, immunochemical, and chromatographic methods have been introduced in this review; a suitable method must be chosen for each laboratory. Although various human sample matrices are available for testing, urine and blood are of the first choices. However, many of these drugs, especially unchanged synthetic cannabinoids, exist in urine and blood for only a short period. Therefore, other matrices that can prove the consumption of these drugs, such as hair and saliva, are likely to receive more attention in the future.

Acknowledgments The authors are thankful to Professors Akira Ishii, Chief Editor, and Osamu Suzuki, Emeritus Chief Editor, Forensic Toxicology, for providing us an opportunity to write this review.

Conflict of Interest There are no financial or other relations that could lead to a conflict of interest.

\section{References}

1. Auwärter V, Dresen S, Weinmann W, Müller M, Pütz M, Ferreirós N (2009) 'Spice' and other herbal blends: harmless incense or cannabinoid designer drugs? J Mass Spectrom 44:832-837

2. Maxwell JC (2014) Psychoactive substances—some new, some old: a scan of the situation in the US. Drug Alcohol Depend 134:71-77

3. Kikura-Hanajiri R, Uchiyama N, Kawamura M, Goda Y (2013) Changes in the prevalence of synthetic cannabinoids and cathinone derivatives in Japan until early 2012. Forensic Toxicol 31:44-53

4. Chung H, Choi H, Heo S, Kim E, Lee J (2014) Synthetic cannabinoids abused in South Korea: drug identifications by the 
National Forensic Service from 2009 to June 2013. Forensic Toxicol 32:82-88

5. Seely KA, Patton AL, Moran CL, Womack ML, Prather PL, Fantegrossi WE, Radominska-Pandya A, Endres GW, Channell KB, Smith NH, McCain KR, James LP, Moran JH (2013) Forensic investigation of K2, Spice, and "bath salt" commercial preparations: a 3-year study of new designer drug products containing synthetic cannabinoid, stimulant, and hallucinogenic compounds. Forensic Sci Int 233:416-422

6. Barratt MJ, Cakic V, Lenton S (2013) Patterns of synthetic cannabinoid use in Australia. Drug Alcohol Rev 32:141-146

7. Caudevilla-Gálligo F, Ventura M, Indave Ruiz BI, Fornís I (2013) Presence and composition of cathinone derivatives in drug samples taken from a drug test service in Spain (2010-2012). Hum Psychopharmacol 28:341-344

8. Presley BC, Jansen-Varnum SA, Logan BK (2013) Analysis of synthetic cannabinoids in botanical materials: a review of analytical methods and findings. Forensic Sci Rev 25:27-46

9. Elsohly MA, Gul W, Wanas AS, Radwan MM (2014) Synthetic cannabinoids: analysis and metabolites. Life Sci 97:78-90

10. Favretto D, Pascali JP, Tagliaro F (2013) New challenges and innovation in forensic toxicology: focus on the "New Psychoactive Substances". J Chromatogr A 1287:84-95

11. Isaacs RCA (2014) A structure-reactivity relationship driven approach to the identification of a color test protocol for the presumptive indication of synthetic cannabimimetic drugs of abuse. Forensic Sci Int 242:135-141

12. Zaitsu K, Katagi M, Nakanishi K, Shima N, Kamata H, Kamata T, Nishioka H, Miki A, Tatsuno M, Iwamura T, Sato T, Tsuchihashi H, Suzuki K (2011) Comprehensive analytical methods of the synthetic cannabinoids appearing in the illicit drug market (in Japanese with English abstract). Jpn J Forensic Sci Tech 16:73-90

13. Logan BK, Reinhold LE, Xu A, Diamond FX (2012) Identification of synthetic cannabinoids in herbal incense blends in the US. J Forensic Sci 57:1168-1180

14. Arntson A, Ofsa B, Lancaster D, Simon JR, McMullin M, Logan B (2013) Validation of a novel immunoassay for the detection of synthetic cannabinoids and metabolites in urine specimens. J Anal Toxicol 37:284-290

15. Hudson S, Ramsey J (2011) The emergence and analysis of synthetic cannabinoids. Drug Test Anal 3:466-478

16. Choi H, Heo S, Choe S, Yang W, Park Y, Kim E, Chung H, Lee J (2013) Simultaneous analysis of synthetic cannabinoids in the materials seized during drug trafficking using GC-MS. Anal Bioanal Chem 405:3937-3944

17. Uchiyama N, Kawamura M, Kikura-Hanajiri R, Goda Y (2012) Identification of two new-type synthetic cannabinoids, $N$-(1adamantyl)-1-pentyl- $1 \mathrm{H}$-indole-3-carboxamide (APICA) and $\mathrm{N}$ (1-adamantyl)-1-pentyl- $1 H$-indazole-3-carboxamide (APINACA), and detection of five synthetic cannabinoids, AM-1220, AM-2233, AM-1241, CB-13 (CRA-13), and AM-1248, as designer drugs in illegal products. Forensic Toxicol 30:114-125

18. Uchiyama N, Matsuda S, Wakana D, Kikura-Hanajiri R, Goda Y (2013) New cannabimimetic indazole derivatives, $N$-(1-amino3-methyl-1-oxobutan-2-yl)-1-pentyl- $1 H$-indazole-3-carboxamide (AB-PINACA) and $N$-(1-amino-3-methyl-1-oxobutan-2-yl)1-(4-fluorobenzyl)- $1 \mathrm{H}$-indazole-3-carboxamide (AB-FUBINACA) identified as designer drugs in illegal products. Forensic Toxicol 31:93-100

19. Uchiyama N, Matsuda S, Kawamura M, Kikura-Hanajiri R, Goda Y (2013) Two new-type cannabimimetic quinolinyl carboxylates, QUPIC and QUCHIC, two new cannabimimetic carboxamide derivatives, ADB-FUBINACA and ADBICA, and five synthetic cannabinoids detected with a thiophene derivative
$\alpha$-PVT and an opioid receptor agonist AH-7921 identified in illegal products. Forensic Toxicol 31:223-240

20. Uchiyama N, Shimokawa Y, Matsuda S, Kawamura M, KikuraHanajiri R, Goda Y (2014) Two new synthetic cannabinoids, AM-2201 benzimidazole analog (FUBIMINA) and (4methylpiperazin-1-yl)(1-pentyl-1H-indol-3-yl)methanone

(MEPIRAPIM), and three phenethylamine derivatives, $25 \mathrm{H}-$ NBOMe 3,4,5-trimethoxybenzyl analog, 25B-NBOMe, and 2C$\mathrm{N}-\mathrm{NBOMe}$, identified in illegal products. Forensic Toxicol 32:105-115

21. Uchiyama N, Shimokawa Y, Kawamura M, Kikura-Hanajiri R, Hakamatsuka $\mathrm{T}$ (2014) Chemical analysis of a benzofuran derivative, 2-(2-ethylaminopropyl)benzofuran (2-EAPB), eight synthetic cannabinoids, five cathinone derivatives, and five other designer drugs newly detected in illegal products. Forensic Toxicol 32:266-281

22. Cox AO, Daw RC, Mason MD, Grabenauer M, Pande PG, Davis KH, Wiley JL, Stout PR, Thomas BF, Huffman JW (2012) Use of SPME-HS-GC-MS for the analysis of herbal products containing synthetic cannabinoids. J Anal Toxicol 36:293-302

23. Ernst L, Krüger K, Lindigkeit R, Schiebel HM, Beuerle T (2012) Synthetic cannabinoids in "spice-like" herbal blends: first appearance of JWH-307 and recurrence of JWH-018 on the German market. Forensic Sci Int 222:216-222

24. Kneisel S, Westphal F, Bisel P, Brecht V, Broecker S, Auwärter V (2012) Identification and structural characterization of the synthetic cannabinoid 3-(1-adamantoyl)-1-pentylindole as an additive in 'herbal incense'. J Mass Spectrom 47:195-200

25. Harris DN, Hokanson S, Miller V, Jackson GP (2014) Fragmentation differences in the EI spectra of three synthetic cannabinoid positional isomers: JWH-250, JWH-302, and JWH201. Int J Mass Spectrom 368:23-29

26. DeRuiter J, Smith FT, Abdel-Hay K, Clark CR (2014) Analytical differentiation of 1-alkyl-3-acylindoles and 1-acyl-3alkylindoles: isomeric synthetic cannabinoids. Anal Chem 86:3801-3808

27. Shevyrin V, Melkozerov V, Nevero A, Eltsov O, Morzherin Y, Shafran Y (2014) 3-Naphthoylindazoles and 2-naphthoylbenzoimidazoles as novel chemical groups of synthetic cannabinoids: chemical structure elucidation, analytical characteristics and identification of the first representatives in smoke mixtures. Forensic Sci Int 242:72-80

28. Ibáñez M, Bijlsma L, van Nuijs ALN, Sancho JV, Haro G, Covaci A, Hernández F (2013) Quadrupole-time-of-flight mass spectrometry screening for synthetic cannabinoids in herbal blends. J Mass Spectrom 48:685-694

29. Grigoryev A, Kavanagh P, Melnik A, Savchuk S, Simonov A (2013) Gas and liquid chromatography-mass spectrometry detection of the urinary metabolites of UR-144 and its major pyrolysis product. J Anal Toxicol 37:265-276

30. Tsujikawa K, Yamamuro T, Kuwayama K, Kanamori T, Iwata YT, Inoue H (2014) Thermal degradation of a new synthetic cannabinoid QUPIC during analysis by gas chromatographymass spectrometry. Forensic Toxicol 32:201-207

31. Sekuła K, Zuba D, Stanaszek R (2012) Identification of naphthoylindoles acting on cannabinoid receptors based on their fragmentation patterns under ESI-QTOFMS. J Mass Spectrom 47:632-643

32. Kneisel S, Auwärter V (2012) Analysis of 30 synthetic cannabinoids in serum by liquid chromatography-electrospray ionization tandem mass spectrometry after liquid-liquid extraction. J Mass Spectrom 47:825-835

33. Scheidweiler KB, Huestis MA (2014) Simultaneous quantification of 20 synthetic cannabinoids and 21 metabolites, and semiquantification of 12 alkyl hydroxy metabolites in human urine 
by liquid chromatography-tandem mass spectrometry. J Chromatogr A 1327:105-117

34. Wohlfarth A, Scheidweiler KB, Chen X, Liu H, Huestis MA (2013) Qualitative confirmation of 9 synthetic cannabinoids and 20 metabolites in human urine using LC-MS/MS and library search. Anal Chem 85:3730-3738

35. Kneisel S, Auwärter V, Kempf J (2013) Analysis of 30 synthetic cannabinoids in oral fluid using liquid chromatography-electrospray ionization tandem mass spectrometry. Drug Test Anal 5:657-669

36. Kneisel S, Speck M, Moosmann B, Corneillie TM, Butlin NG, Auwärter V (2013) LC/ESI-MS/MS method for quantification of 28 synthetic cannabinoids in neat oral fluid and its application to preliminary studies on their detection windows. Anal Bioanal Chem 405:4691-4706

37. Hutter M, Kneisel S, Auwärter V, Neukamm MA (2012) Determination of 22 synthetic cannabinoids in human hair by liquid chromatography-tandem mass spectrometry. J Chromatogr B 903:95-101

38. Teske J, Weller JP, Fieguth A, Rothämel T, Schulz Y, Tröger HD (2010) Sensitive and rapid quantification of the cannabinoid receptor agonist naphthalen-1-yl-(1-pentylindol-3-yl)methanone (JWH-018) in human serum by liquid chromatography-tandem mass spectrometry. J Chromatogr B 878:2659-2663

39. Kacinko SL, Xu A, Homan JW, McMullin MM, Warrington DM, Logan BK (2011) Development and validation of a liquid chromatography-tandem mass spectrometry method for the identification and quantification of JWH-018, JWH-073, JWH-019, and JWH-250 in human whole blood. J Anal Toxicol 35:386-393

40. Yeakel JK, Logan BK (2013) Blood synthetic cannabinoid concentrations in cases of suspected impaired driving. J Anal Toxicol 37:547-551

41. Dresen S, Kneisel S, Weinmann W, Zimmermann R, Auwärter V (2011) Development and validation of a liquid chromatography-tandem mass spectrometry method for the quantitation of synthetic cannabinoids of the aminoalkylindole type and methanandamide in serum and its application to forensic samples. J Mass Spectrom 46:163-171

42. Moran CL, Le VH, Chimalakonda KC, Smedley AL, Lackey FD, Owen SN, Kennedy PD, Endres GW, Ciske FL, Kramer JB, Kornilov AM, Bratton LD, Dobrowolski PJ, Wessinger WD, Fantegrossi WE, Prather PL, James LP, Radominska-Pandya A, Moran JH (2011) Quantitative measurement of JWH-018 and JWH-073 metabolites excreted in human urine. Anal Chem 83:4228-4236

43. Chimalakonda KC, Moran CL, Kennedy PD, Endres GW, Uzieblo A, Dobrowolski PJ, Fifer EK, Lapoint J, Nelson LS, Hoffman RS, James LP, Radominska-Pandya A, Moran JH (2011) Solid-phase extraction and quantitative measurement of omega and omega-1 metabolites of JWH-018 and JWH-073 in human urine. Anal Chem 83:6381-6388

44. de Jager AD, Warner JV, Henman M, Ferguson W, Hall A (2012) LC-MS/MS method for the quantitation of metabolites of eight commonly used synthetic cannabinoids in human urine-an Australian perspective. J Chromatogr B 897:22-31

45. Yanes EG, Lovett DP (2012) High-throughput bioanalytical method for analysis of synthetic cannabinoid metabolites in urine using salting-out sample preparation and LC-MS/MS. J Chromatogr B 909:42-50

46. Hermanns-Clausen M, Kneisel S, Szabo B, Auwärter V (2013) Acute toxicity due to the confirmed consumption of synthetic cannabinoids: clinical and laboratory findings. Addiction 108:534-544

47. Hermanns-Clausen M, Kneisel S, Hutter M, Szabo B, Auwärter V (2013) Acute intoxication by synthetic cannabinoids-four case reports. Drug Test Anal 5:790-794
48. Musshoff F, Madea B, Kernbach-Wighton G, Bicker W, Kneisel S, Hutter M, Auwärter V (2014) Driving under the influence of synthetic cannabinoids ("Spice"): a case series. Int J Legal Med 128:59-64

49. Hutter M, Broecker S, Kneisel S, Auwärter V (2012) Identification of the major urinary metabolites in man of seven synthetic cannabinoids of the aminoalkylindole type present as adulterants in herbal mixtures using LC-MS/MS techniques. J Mass Spectrom 47:54-65

50. Shanks KG, Dahn T, Terrell AR (2012) Detection of JWH-018 and JWH-073 by UPLC-MS-MS in postmortem whole blood casework. J Anal Toxicol 36:145-152

51. Adamowicz P, Zuba D, Sekuła K (2013) Analysis of UR-144 and its pyrolysis product in blood and their metabolites in urine. Forensic Sci Int 233:320-327

52. Saito T, Namera A, Miura N, Ohta S, Miyazaki S, Osawa M, Inokuchi S (2013) A fatal case of MAM-2201 poisoning. Forensic Toxicol 31:333-337

53. Behonick G, Shanks KG, Firchau DJ, Mathur G, Lynch CF, Nashelsky M, Jaskierny DJ, Meroueh C (2014) Four postmortem case reports with quantitative detection of the synthetic cannabinoid, 5F-PB-22. J Anal Toxicol 38:559-562

54. Mazzarino M, de la Torre X, Botrè F (2014) A liquid chromatography-mass spectrometry method based on class characteristic fragmentation pathways to detect the class of indolederivative synthetic cannabinoids in biological samples. Anal Chim Acta 837:70-82

55. Wood DM, Dargan PI (2012) Mephedrone (4-methylmethcathinone): what is new in our understanding of its use and toxicity. Prog Neuro-Psychopharmacol Biol Psychiatry 39:227-233

56. Uchiyama N, Kawamura M, Kamakura H, Kikura-Hanajiri R, Goda Y (2008) Analytical data of designated substances (Shiteiyakubutsu) controlled by the pharmaceutical affairs law in Japan, part II: color test and TLC (in Japanese with English abstract). Yakugaku Zasshi 128:981-987

57. Dal Cason TA (1997) The characterization of some 3,4methylenedioxycathinone (MDCATH) homologs. Forensic Sci Int 87:9-53

58. Swortwood MJ, Hearn WL, DeCaprio AP (2014) Cross-reactivity of designer drugs, including cathinone derivatives, in commercial enzyme-linked immunosorbent assays. Drug Test Anal 6:716-727

59. Ellefsen KN, Anizan S, Castaneto MS, Desrosiers NA, Martin TM, Klette KL, Huestis MA (2014) Validation of the only commercially available immunoassay for synthetic cathinones in urine: randox drugs of abuse $\mathrm{V}$ biochip array technology. Drug Test Anal 6:728-738

60. Penders TM, Gestring RE, Vilensky DA (2012) Intoxication delirium following use of synthetic cathinone derivatives. Am J Drug Alcohol Abuse 38:616-617

61. Zuba D (2012) Identification of cathinones and other active components of legal highs by mass spectrometric methods. Trends Anal Chem 32:15-30

62. Matsuta S, Katagi M, Nishioka H, Kamata H, Sasaki K, Shima N, Kamata T, Miki A, Tatsuno M, Zaitsu K, Tsuboi K, Tsuchihashi H, Suzuki K (2014) Structural characterization of cathinone-type designer drugs by EI mass spectrometry (in Japanese with English abstract). Jpn J Forensic Sci Tech 19:77-89

63. Brandt SD, Sumnall HR, Measham F, Cole J (2010) Analyses of second-generation 'legal highs' in the UK: initial findings. Drug Test Anal 2:377-382

64. Brandt SD, Freeman S, Sumnall HR, Measham F, Cole J (2011) Analysis of NRG 'legal highs' in the UK: identification and formation of novel cathinones. Drug Test Anal 3:569-575 
65. Fornal E (2013) Identification of substituted cathinones: 3,4methylenedioxy derivatives by high performance liquid chromatography-quadrupole time of flight mass spectrometry. J Pharm Biomed Anal 81-82:13-19

66. Jankovics P, Váradi A, Tölgyesi L, Lohner S, Németh-Palotás J, Koszegi-Szalai H (2011) Identification and characterization of the new designer drug 4'-methylethcathinone (4-MEC) and elaboration of a novel liquid chromatography-tandem mass spectrometry (LC-MS/MS) screening method for seven different methcathinone analogs. Forensic Sci Int 210:213-220

67. Westphal F, Junge T (2012) Ring positional differentiation of isomeric $\mathrm{N}$-alkylated fluorocathinones by gas chromatography/tandem mass spectrometry. Forensic Sci Int 223:97-105

68. Meyer MR, Du P, Schuster F, Maurer HH (2010) Studies on the metabolism of the $\alpha$-pyrrolidinophenone designer drug methylenedioxy-pyrovalerone (MDPV) in rat and human urine and human liver microsomes using GC-MS and LC-highresolution MS and its detectability in urine by GC-MS. J Mass Spectrom 45:1426-1442

69. Strano-Rossi S, Cadwallader AB, de la Torre X, Botrè F (2010) Toxicological determination and in vitro metabolism of the designer drug methylenedioxypyrovalerone (MDPV) by gas chromatography/mass spectrometry and liquid chromatography/ quadrupole time-of-flight mass spectrometry. Rapid Commun Mass Spectrom 24:2706-2714

70. Spiller HA, Ryan ML, Weston RG, Jansen J (2011) Clinical experience with and analytical confirmation of "bath salts" and "legal highs" (synthetic cathinones) in the US. Clin Toxicol 49:499-505

71. Ojanperä IA, Heikman PK, Rasanen IJ (2011) Urine analysis of 3,4-methylenedioxypyrovalerone in opioid-dependent patients by gas chromatography-mass spectrometry. Ther Drug Monit 33:257-263

72. Pearson JM, Hargraves TL, Hair LS, Massucci CJ, Frazee CC 3rd, Garg U, Pietak BR (2012) Three fatal intoxications due to methylone. J Anal Toxicol 36:444-451

73. Saito T, Namera A, Osawa M, Aoki H, Inokuchi S (2013) SPME-GC-MS analysis of $\alpha$-pyrrolidinovaleorophenone in blood in a fatal poisoning case. Forensic Toxicol 31:328-332

74. Namera A, Urabe S, Saito T, Torikoshi-Hatano A, Shiraishi H, Arima Y, Nagao M (2013) A fatal case of 3,4-methylenedioxypyrovalerone poisoning: coexistence of $\alpha$-pyrrolidinobutiophenone and $\alpha$-pyrrolidinovalerophenone in blood and/or hair. Forensic Toxicol 31:338-343

75. Wyman JF, Lavins ES, Engelhart D, Armstrong EJ, Snell KD, Boggs PD, Taylor SM, Norris RN, Miller FP (2013) Postmortem tissue distribution of MDPV following lethal intoxication by bath salts. J Anal Toxicol 37:182-185

76. Wright TH, Cline-Parhamovich K, Lajoie D, Parsons L, Dunn M, Ferslew KE (2013) Deaths involving methylenedioxypyrovalerone (MDPV) in Upper East Tennessee. J Forensic Sci 58:1558-1562

77. Shima N, Katagi M, Kamata H, Matsuta S, Nakanishi K, Zaitsu K, Kamata T, Nishioka H, Miki A, Tatsuno M, Sato T, Tsuchihashi H, Suzuki K (2013) Urinary excretion and metabolism of the newly encountered designer drug 3,4-dimethylmethcathinone in humans. Forensic Toxicol 31:101-112

78. Uralets V, Rana S, Morgan S, Ross W (2014) Testing for designer stimulants: metabolic profiles of 16 synthetic cathinones excreted free in human urine. J Anal Toxicol 38:233-241

79. Shima N, Katagi M, Kamata H, Matsuta S, Sasaki K, Kamata T, Nishioka H, Miki A, Tatsuno M, Zaitsu K, Ishii A, Sato T, Tsuchihashi H, Suzuki K (2014) Metabolism of the newly encountered designer drug $\alpha$-pyrrolidinovalerophenone in humans: identification and quantitation of urinary metabolites. Forensic Toxicol 32:59-67
80. Swortwood MJ, Boland DM, DeCaprio AP (2013) Determination of 32 cathinone derivatives and other designer drugs in serum by comprehensive LC-QQQ-MS/MS analysis. Anal Bioanal Chem 405:1383-1397

81. Concheiro M, Anizan S, Ellefsen K, Huestis MA (2013) Simultaneous quantification of 28 synthetic cathinones and metabolites in urine by liquid chromatography-high resolution mass spectrometry. Anal Bioanal Chem 405:9437-9448

82. Sørensen LK (2011) Determination of cathinones and related ephedrines in forensic whole-blood samples by liquid chromatography-electrospray tandem mass spectrometry. J Chromatogr B 879:727-736

83. Kriikku P, Wilhelm L, Schwarz O, Rintatalo J (2011) New designer drug of abuse: 3,4-methylenedioxypyrovalerone (MDPV). Findings from apprehended drivers in Finland. Forensic Sci Int 210:195-200

84. Maskell PD, De Paoli G, Seneviratne C, Pounder DJ (2011) Mephedrone (4-methylmethcathinone)-related deaths. J Anal Toxicol 35:188-191

85. Rust KY, Baumgartner MR, Dally AM, Kraemer T (2012) Prevalence of new psychoactive substances: a retrospective study in hair. Drug Test Anal 4:402-408

86. Rojek S, Kłys M, Strona M, Maciow M, Kula K (2012) "Legal highs"- toxicity in the clinical and medico-legal aspect as exemplified by suicide with bk-MBDB administration. Forensic Sci Int 222:e1-e6

87. Gil D, Adamowicz P, Skulska A, Tokarczyk B, Stanaszek R (2013) Analysis of 4-MEC in biological and non-biological material-three case reports. Forensic Sci Int 228:e11-e15

88. Adamowicz P, Tokarczyk B, Stanaszek R, Slopianka M (2013) Fatal mephedrone intoxication-a case report. J Anal Toxicol $37: 37-42$

89. Johnson RD, Botch-Jones SR (2013) The stability of four designer drugs: MDPV, mephedrone, BZP and TFMPP in three biological matrices under various storage conditions. J Anal Toxicol 37:51-55

90. Cosbey SH, Peters KL, Quinn A, Bentley A (2013) Mephedrone (methylmethcathinone) in toxicology casework: a Northern Ireland perspective. J Anal Toxicol 37:74-82

91. Marinetti LJ, Antonides HM (2013) Analysis of synthetic cathinones commonly found in bath salts in human performance and postmortem toxicology: method development, drug distribution and interpretation of results. J Anal Toxicol 37:135-146

92. Adamowicz P, Gil D, Skulska A, Tokarczyk B (2013) Analysis of MDPV in blood-determination and interpretation. J Anal Toxicol 37:308-312

93. Zuba D, Adamowicz P, Byrska B (2013) Detection of buphedrone in biological and non-biological material-two case reports. Forensic Sci Int 227:15-20

94. Anizan S, Ellefsen K, Concheiro M, Suzuki M, Rice KC, Baumann MH, Huestis MA (2014) 3,4-Methylenedioxypyrovalerone (MDPV) and metabolites quantification in human and rat plasma by liquid chromatography-high resolution mass spectrometry. Anal Chim Acta 827:54-63

95. Wurita A, Hasegawa K, Minakata K, Gonmori K, Nozawa H, Yamagishi I, Suzuki O, Watanabe K (2014) Postmortem distribution of $\alpha$-pyrrolidinobutiophenone in body fluids and solid tissues of a human cadaver. Leg Med 16:241-246

96. Usui K, Aramaki T, Hashiyada M, Hayashizaki Y, Funayama M (2014) Quantitative analysis of 3,4-dimethylmethcathinone in blood and urine by liquid chromatography-tandem mass spectrometry in a fatal case. Leg Med 16:222-226

97. Bertol E, Mari F, Berto RB, Mannaioni G, Vaiano F, Favretto D (2014) A mixed MDPV and benzodiazepine intoxication in a chronic drug abuser: determination of MDPV metabolites by 
LC-HRMS and discussion of the case. Forensic Sci Int 243:149-155

98. Hasegawa K, Wurita A, Minakata K, Gonmori K, Nozawa H, Yamagishi I, Suzuki O, Watanabe K (2014) Identification and quantitation of a new cathinone designer drug PV9 in an "aroma liquid" product, antemortem whole blood and urine specimens, and a postmortem whole blood specimen in a fatal poisoning case. Forensic Toxicol 32:243-250

99. Bijlsma L, Sancho JV, Hernández F, Niessen WMA (2011) Fragmentation pathways of drugs of abuse and their metabolites based on QTOF MS/MS and $\mathrm{MSE}^{\mathrm{E}}$ accurate-mass spectra. J Mass Spectrom 46:865-875

100. Patton AL, Chimalakonda KC, Moran CL, McCain KR, Radominska-Pandya A, James LP, Kokes C, Moran JH (2013) K2 toxicity: fatal case of psychiatric complications following AM2201 exposure. J Forensic Sci 58:1676-1680

101. Springer D, Fritschi G, Maurer HH (2003) Metabolism of the new designer drug alpha-pyrrolidinopropiophenone (PPP) and the toxicological detection of PPP and $4^{\prime}$-methyl-alpha-pyrrolidinopropiophenone (MPPP) studied in rat urine using gas chromatography-mass spectrometry. J Chromatogr B 796:253-266

102. Sauer C, Peters FT, Haas C, Meyer MR, Fritschi G, Maurer HH (2009) New designer drug alpha-pyrrolidinovalerophenone (PVP): studies on its metabolism and toxicological detection in rat urine using gas chromatographic/mass spectrometric techniques. J Mass Spectrom 44:952-964

103. Tyrkkö E, Pelander A, Ketola RA, Ojanperä I (2013) In silico and in vitro metabolism studies support identification of designer drugs in human urine by liquid chromatography/quadrupole-time-of-flight mass spectrometry. Anal Bioanal Chem 405:6697-6709
104. Namera A, Konuma K, Kawamura M, Saito T, Nakamoto A, Yahata M, Ohta S, Miyazaki S, Shiraishi H, Nagao M (2014) Time-course profile of urinary excretion of intravenously administered $\alpha$-pyrrolidinovalerophenone and $\alpha$-pyrrolidinobutiophenone in a human. Forensic Toxicol 32:68-74

105. Kovács K, Tóth AR, Kereszty EM (2012) A new designer drug: methylone related death. Orv Hetil 153:271-276

106. Cawrse BM, Levine B, Jufer RA, Fowler DR, Vorce SP, Dickson AJ, Holler JM (2012) Distribution of methylone in four postmortem cases. J Anal Toxicol 36:434-439

107. Torrance H, Cooper G (2010) The detection of mephedrone (4methylmethcathinone) in 4 fatalities in Scotland. Forensic Sci Int 202:e62-e63

108. Lusthof KJ, Oosting R, Maes A, Verschraagen M, Dijkhuizen A, Sprong AG (2011) A case of extreme agitation and death after the use of mephedrone in The Netherlands. Forensic Sci Int 206:e93-e95

109. Hasegawa K, Suzuki O, Wurita A, Minakata K, Yamagishi I, Nozawa H, Gonmori K, Watanabe K (2014) Postmortem distribution of $\alpha$-pyrrolidinovalerophenone and its metabolite in body fluids and solid tissues in a fatal poisoning case measured by LC-MS-MS with the standard addition method. Forensic Toxicol 32:225-234

110. Murray BL, Murphy CM, Beuhler MC (2012) Death following recreational use of designer drug "bath salts" containing 3,4methylenedioxypyrovalerone (MDPV). J Med Toxicol 8:69-75

111. Kesha K, Boggs CL, Ripple MG, Allan CH, Levine B, JuferPhipps R, Doyon S, Chi P, Fowler DR (2013) Methylenedioxypyrovalerone ("bath salts"), related death: case report and review of the literature. J Forensic Sci 58:1654-1659 